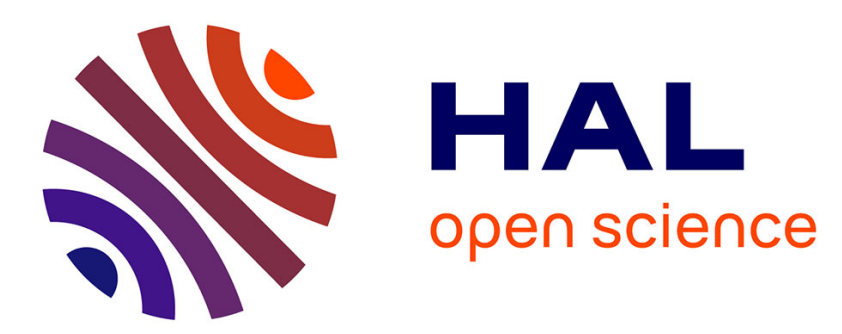

\title{
Horizontal collaborative transport: survey of solutions and practical implementation issues
}

Shenle Pan, Damien Trentesaux, Eric Ballot, George Q. Huang

\section{To cite this version:}

Shenle Pan, Damien Trentesaux, Eric Ballot, George Q. Huang. Horizontal collaborative transport: survey of solutions and practical implementation issues. International Journal of Production Research, inPress, 57 (15-16), pp.5340-5361. 10.1080/00207543.2019.1574040 . hal-02008934

\section{HAL Id: hal-02008934}

https://hal-mines-paristech.archives-ouvertes.fr/hal-02008934

Submitted on 6 Feb 2019

HAL is a multi-disciplinary open access archive for the deposit and dissemination of scientific research documents, whether they are published or not. The documents may come from teaching and research institutions in France or abroad, or from public or private research centers.
L'archive ouverte pluridisciplinaire HAL, est destinée au dépôt et à la diffusion de documents scientifiques de niveau recherche, publiés ou non, émanant des établissements d'enseignement et de recherche français ou étrangers, des laboratoires publics ou privés. 


\title{
Horizontal Collaborative Transport: survey of solutions and practical implementation issues
}

\author{
Shenle Pan ${ }^{\mathrm{a} *}$, Damien Trentesaux ${ }^{\mathrm{b}}$, Eric Ballot ${ }^{\mathrm{a}}$ and George Q. Huang ${ }^{\mathrm{c}}$ \\ ${ }^{a}$ Centre de Gestion Scientifique - I3 - UMR CNRS 9217, MINES ParisTech, PSL Research \\ University, Paris, France; \\ ${ }^{b}$ LAMIH, UMR CNRS 8201, University of Valenciennes and Hainaut-Cambrésis, Valenciennes, \\ France; \\ ${ }^{c}$ Department of Industrial and Manufacturing \\ Systems Engineering, The University of Hong Kong, Hong Kong, People's Republic of China
}

(Received 16 May 2018; accepted 17 January 2019)

To cite this article: Shenle Pan, Damien Trentesaux, Eric Ballot \& George Q. Huang (2019):

Horizontal collaborative transport: survey of solutions and practical implementation issues, International Journal of Production Research, DOI: 10.1080/00207543.2019.1574040

To link to this article: https://doi.org/10.1080/00207543.2019.1574040

\begin{abstract}
Horizontal collaboration has been considered as effective practice for sustainable logistics and freight transport and it has gained increased attention in recent years. This paper aims to provide a survey of the development of horizontal collaborative transport (HCT) over the past ten years, to identify research trends and gaps, then to propose some research opportunities. The paper also aims to provide guidelines to logistics companies who wish to embark on HCT, to help them choose which HCT solution to implement. To provide a comprehensive and structured review, the paper follows the methodology in the literature. A total of 120 scientific papers published between 2007 and 2017 were reviewed. A survey framework based on two axes - HCT solutions and implementation issues - is developed to analyse and position the papers. The results show that, regarding HCT solutions, carrier alliance and flow controller collaboration were the most frequently studied. But recent innovative solutions such as pooling and physical internet are also gaining increased attention. Regarding implementation issues, the focus of the literature has been on the development of decision-making models, including transport planning, lane exchange, and gain sharing. Conversely, managerial and technological issues have received less attention.
\end{abstract}

Keywords: Survey; Horizontal Collaboration; Freight Transport; Solutions and Practical Implementation issues; Sustainability.

\section{Introduction}

Over the past decades, sustainability in freight transport has become a major preoccupation in the field of logistics (McKinnon et al., 2015, Zhu et al., 2018). On one hand, freight transport is a lever for economic growth and on the other hand, it contributes significantly to problems such as $\mathrm{CO}_{2}$ emissions, road accidents, and congestion in many countries (Piecyk and McKinnon, 2010, Goldsby et al., 2014). More effective and efficient organisation of freight transport has become crucial to succeed in logistics, as well as to deal with sustainability challenges.

Collaboration between logistics players has been recognised as one of the most effective approaches to improve freight transport efficiency for sustainability 
(Goldsby et al., 2014). Although cooperation, coordination, and collaboration should be differentiated, the term "collaboration" is used in this paper to broadly cover collaborative partnerships in transport and logistics from operational level to strategic level (see Spekman et al. (1998) for the definitions, which is beyond the scope of this paper). As discussed in Mason et al. (2007), there are two types of collaboration in logistics: vertical collaboration (VC) and horizontal collaboration (HC). VC focuses on the beneficial vertical relationships between players within a supply chain (SC). It has been widely studied in the literature and there exist several surveys, for example Barratt (2004), Power (2005) and Stadtler (2009).

$\mathrm{HC}$ is more recent and concerns collaboration across SCs. Generally speaking, HC refers to "active cooperation between two or more firms that operate at the same level of the supply chain...", between shippers, between Logistics Service Providers (LSPs), or between receivers for example (Cruijssen, 2006, Mason et al., 2007). Some successful examples of $\mathrm{HC}$ can be found in passenger transport with airline alliances such as Skyteam and Star Alliance.

Specifically, in the field of freight transport, the development of $\mathrm{HC}$ can be observed from both industrial and academic viewpoints. From an industrial viewpoint, HC is not new, especially in the trucking industry. Well-known examples include the European carrier association ASTRE (ASTRE, 2016) that was created to help independent carriers exchange transport requests. Over the past decade, companies have been looking for greater synergy in freight transport to mitigate the higher pressure of logistics costs and demanding services (Cruijssen, 2006). As a result, collaboration across independent SCs which is more extensive and efficient has been considered as an innovative freight transport and logistics solution (Mason et al., 2007, Cruijssen, 2006, Schmoltzi and Wallenburg, 2011). The case of four collaborating manufacturers in France (Mars, UB, Wrigley and Saupiquet) is one of the success stories (CO3, 2014). More examples can be found in Saenz et al. (2015). From an academic viewpoint, $\mathrm{HC}$ is a relatively young but rapidly evolving stream for which new lines of research can be observed. In recent years, a number of relevant concepts, methods, and models have been initiated and studied (see Section 4). These contributions promote $\mathrm{HC}$ in freight transport from carrier to SC level, and more recently at supply network level.

Considering the importance and rapid development of $\mathrm{HC}$ in freight transport, this paper focuses exclusively on this topic which is termed herein "horizontal collaborative transport" (HCT). As there is currently no collective definition of HCT, this paper offers a broad, generic one: HCT refers to all types of horizontal cooperation or collaboration in freight transport between players operating at the same level of the supply chain (carriers, logistics service providers, shippers or receivers), between independent supply chains, and between transport networks, from occasional cooperation to long-lasting collaboration, and from operational level to strategic level. This definition is broad enough to cover the related literature concerning cooperation, coordination, and collaboration in freight transport, and to help provide us with an exhaustive review of the domain. The definition also suggests that HCT can be achieved from various perspectives from transport to supply chain level, from operational to strategic level, or from carrier to flow controller level. In this paper, we use the term "HCT solutions" to cover all concepts, methods, and models aimed at achieving HCT. The survey will then cover as many HCT solutions 
as possible, especially those recent breakthroughs. It should be noticed that the paper focuses exclusively on collaboration, competition between companies is not considered.

This paper aims to make several contributions that differ from other review or survey papers related to HCT. Five review papers were identified from the literature. Nagarajan and Sošić (2008) and Guajardo and Rönnqvist (2016) review the applications of cooperative game theory in HCT with regard to coalition formation and gain sharing issues. Stadtler (2009) provides a comprehensive review of optimisation models for collaborative transport planning at operational level. Cruijssen et al. (2007c) provide a broad review of horizontal cooperation in logistics according to the literature up to 2007. As horizontal cooperation was still in its infancy at the time, they discuss the perspectives according to drivers, impediments, and facilitators. HCT solutions were not the focus of the paper. Verdonck et al. (2013) review request reallocation techniques between carriers in the context of a carrier alliance, but they do not look into other HCT solutions. Overall, the current review papers focus on either one specific HCT solution or one specific implementation issue, but no comprehensive and structured review has been published regarding all existing HCT solutions and implementation issues.

In addition to the lack of comprehensive and structured review of HCT, this work is also motivated by two research questions that have not been addressed adequately.

- First, from an industrial perspective, what are the existing practicable HCT solutions? And how should logistics companies (e.g., carriers, LSP, shippers, receivers) adopt effective and efficient $\mathrm{HCT}$ solutions, by taking into account their position, resources, and responsibility in the $\mathrm{SC}$, while being aware of the underlying issues and challenges when implementing the solutions (called implementation issues in this paper)?

- Second, from an academic perspective, what are the current trends of solution innovation? And how can these innovative solutions stimulate current research problems or bring up new problems to the field?

To answer these questions, we aim to conduct a comprehensive, exhaustive, and structured review of recent research and practices on HCT solutions and relevant implementation issues. Accordingly, the contribution of the work can be justified from industrial and academic perspectives. Through the survey, we aim to provide guidelines to logistics companies who wish to embark on HCT, to help them choose which HCT solution to implement. Furthermore, significant findings and research gaps will point out emerging research prospects and opportunities in the field of HCT.

To provide a comprehensive and structured review, the paper follows the guidelines for Systematic Literature Review (SLR) in Supply Chain Management studied in Durach et al. (2017). The SLR method comprises 6 steps, they are (1) Define research question, (2) Determine study inclusion/exclusion criteria, (3) Search potentially relevant literature, (4) Select pertinent literature, (5) Synthesize literature, and (6) Report the results.

After the introduction, Section 2 explains the paper selection methodology used. Section 3 presents the dual-axis survey framework, i.e., HCT solutions and 
implementation issues. Under the framework, Sections 4 and 5 discuss axis-by-axis the contribution of each paper. These sections are the body of the survey. Then, in Section 6, a cross table comparing the two axes is presented to position the studies and to analyse research trends and gaps. Some research prospects are discussed in Section 7. Finally, Section 8 concludes this work.

\section{Paper Selection Methodology}

To select relevant papers from the literature, we followed the Step (2)-(4) in the SLR method (Durach et al., 2017). The paper selection methodology used in this work comprised three steps, as shown in the following table:

\begin{tabular}{|l|l|}
\hline Step 1 - Criteria for inclusion & Reasoning \\
\hline $\begin{array}{l}\text { Paper published from } 2007 \text { to } 2017 \text { (available } \\
\text { online included) }\end{array}$ & $\begin{array}{l}\text { Papers published over the past ten years and } \\
\text { after Cruijssen et al. (2007c) }\end{array}$ \\
\hline $\begin{array}{l}\text { Paper published in peer-reviewed academic } \\
\text { journals focusing on logistics }\end{array}$ & To focus on high quality publications \\
\hline Paper written in English & $\begin{array}{l}\text { English is the dominant language in SC and } \\
\text { logistics research }\end{array}$ \\
\hline $\begin{array}{l}\text { Paper investigating freight transport and on } \\
\text { horizontal collaboration }\end{array}$ & This is the research problem of this work \\
\hline Step 2 - Data search & \\
\hline $\begin{array}{l}\text { This step is concerned with two tasks. } \\
\text { The first task was to select data sources. Firstly, Google Scholar and Web of Science } \\
\text { which are the two most important databases were used to search for a raw set of } \\
\text { publications of interest. This set was completed with papers from a search from other } \\
\text { databases of international editor such as ScienceDirect, Taylor \& Francis, Wiley Online } \\
\begin{array}{l}\text { Library, Emerald, and Springer. This has been done to avoid missing any publications } \\
\text { from peer-reviewed academic journals. }\end{array} \\
\text { - The second task was to define the list of keywords and construct database queries. The } \\
\text { keywords were defined by two rounds of searching. The first round started with } \\
\text { searching and reviewing papers having the two main terms that represent HCT: } \\
\text { "horizontal collaboration" and "freight transport (or transportation)", plus some of the } \\
\text { closest synonyms words of the latter, namely "logistics", "shipper/receivers", and } \\
\text { "service providers". Then the second round consisted in a refinement searching in which } \\
\text { correlated keywords identified from the primary review were added, namely "horizontal } \\
\text { cooperation", "carrier collaboration", "collaborative transport", "carrier (or logistics) } \\
\text { alliances", "pooling", "transport marketplace", "freight marketplace", and "Physical } \\
\text { Internet". }\end{array}$ \\
\hline $\begin{array}{l}\text { Step 3 - Paper selection } \\
\text { A total of 136 papers were identified after step 2. Step 3 involved studying the problem } \\
\text { domain of these papers to filter out those not focusing on HCT, following which 16 papers } \\
\text { were excluded from the survey for the reasons of either not focusing on transport, or not } \\
\text { focusing on HC. }\end{array}$ \\
\hline
\end{tabular}

Table 1. Three step paper selection methodology (adapted from Durach et al. (2017))

As a result, 120 papers from 37 journals were finally selected for the survey. All cited journals are listed in Appendix A. Figure 1 illustrates the number of papers from 2007 to 2017. We can see that, overall, HCT has gained increased attention in the literature. 


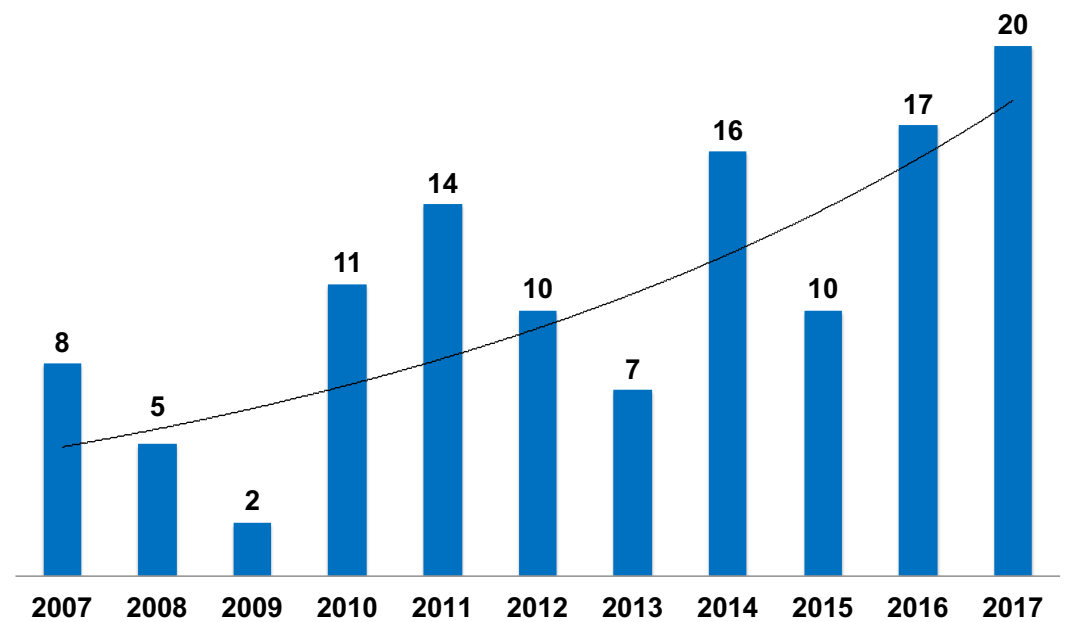

Figure 1. Number of papers selected from 2007 to 2017 (120 in total, including online papers)

\section{Survey Framework}

Once relevant papers are identified, Step (5) synthesize literature then Step (6) Report the results, following SLR method (Durach et al., 2017) are triggered. Based on the research questions presented in Section 1, the identification and the classification of the currently existing HCT solutions are realised, then an investigation about the practicability of each is done. As a result, a two-axis framework is proposed to position relatively the selected papers: Axis 1 dealing with HCT solutions, and Axis 2 dealing with implementation issues. Moreover, the research methodology used in the reviewed papers are also considered to investigate how were the issues addressed. By such, all the papers selected can be classified and coded by Author, Year of publication, HCT solution category, Implementation issue category, and Methodology of the paper, as shown in Table 2.

The first axis of classification is called HCT solutions. All HCT concepts, methods, and models reported in the papers reviewed could be classified into six classes of solutions: Single carrier collaboration (S1); Carrier Alliance/Coalition (S2); Transport Marketplace (S3); flow-controlling entities collaboration (S4); Logistics pooling (S5); Physical Internet (S6).

The second axis of classification focuses on the implementation issues involved in HCT solutions. Overall, seven classes could be observed from the literature: Collaborative network design (I1); Transport planning optimisation (I2); Mechanism for exchanging requests (I3); Gain sharing (I4); Communications technology (I5); Organisation (I6); Management and governance (I7).

The next two sections will study in depth the two axes of classification and their subclasses. A cross table of the two axes is also provided in Section 6. The existing literature will then be positioned accordingly, enabling us to identify their contributions, as well as research gaps in the current state of the art. This will, in turn, enable some future research prospects to be deduced. 


\begin{tabular}{|c|c|c|c|}
\hline Study & Solutions & Implementation Issues & Methodology \\
\hline Hernández and Peeta (2014) & S1 & I2 & Experimental \\
\hline Hernández et al. (2011) & S1 & I2 & Experimental \\
\hline Puettmann and Stadtler (2010) & S1 & I2 & Experimental \\
\hline Buijs et al. (2016) & S1 & I6 & Experimental \\
\hline Wang et al. (2014a) & S2 & I1 & Experimental \\
\hline Hernández et al. (2012) & S2 & I1 & Experimental \\
\hline Dahl and Derigs (2011) & S2 & I2 & Experimental \\
\hline Dai and Chen (2012a) & S2 & I2 & Experimental \\
\hline Lin and $\mathrm{Ng}(2012)$ & S2 & I2 & Experimental \\
\hline Liu et al. (2010a) & S2 & I2 & Experimental \\
\hline Liu et al. (2010b) & S2 & I2 & Experimental \\
\hline Wang and Kopfer (2014) & S2 & I2 & Experimental \\
\hline Wang and Kopfer (2015) & S2 & $\mathrm{I} 2$ & Experimental \\
\hline Fernández et al. (2016) & S2 & I2 & Experimental \\
\hline Caballini et al. (2016) & S2 & I2 & Experimental \\
\hline Hernández and Peeta (2011) & S2 & I2 & Experimental \\
\hline Bailey et al. (2011) & $\mathrm{S} 2$ & I2 & Experimental \\
\hline Wang et al. (2014b) & S2 & I2 & Experimental \\
\hline Montoya-Torres et al. (2016) & S2 & $\mathrm{I} 2$ & Experimental \\
\hline Defryn and Sörensen (2018) & S2 & $\mathrm{I} 2$ & Experimental \\
\hline Zhang et al. (2017) & S2 & I2 & Experimental \\
\hline Muñoz-Villamizar et al. (2017) & S2 & I2 & Experimental \\
\hline Molenbruch et al. (2017) & S2 & I2 & Experimental \\
\hline Defryn et al. (2017) & $\mathrm{S} 2$ & $\mathrm{I} 2$ & Experimental \\
\hline Fernández et al. (2018) & S2 & I2 & Experimental \\
\hline Li et al. (2015) & S2 & I3 & Experimental \\
\hline Agarwal and Ergun (2008) & S2 & I3 & Experimental \\
\hline Agarwal and Ergun (2010) & $\mathrm{S} 2$ & I3 & Experimental \\
\hline Dai and Chen (2011) & S2 & I3 & Experimental \\
\hline Houghtalen et al. (2011) & S2 & $\mathrm{I} 3$ & Experimental \\
\hline Kuo and Miller-Hooks (2012) & S2 & $\mathrm{I} 3$ & Experimental \\
\hline Verdonck et al. (2013) & S2 & $\mathrm{I} 3$ & Review \\
\hline Berger and Bierwirth (2010) & S2 & $\mathrm{I} 3$ & Experimental \\
\hline Zhou et al. (2011) & S2 & $\mathrm{I} 3$ & Experimental \\
\hline Özener et al. (2011) & $\mathrm{S} 2$ & I3 & Experimental \\
\hline Chen (2016) & S2 & $\mathrm{I} 3$ & Experimental \\
\hline Dai et al. (2014) & S2 & $\mathrm{I} 3$ & Experimental \\
\hline Lai et al. (2017) & S2 & I3 & Experimental \\
\hline Dai and Chen (2012b) & S2 & I4 & Experimental \\
\hline Krajewska et al. (2008) & S2 & I4 & Experimental \\
\hline Verdonck et al; (2016) & S2 & I4 & Experimental \\
\hline Buijs and Wortmann (2014) & S2 & I5 & Exploratory \\
\hline Allen et al. (2017) & S2 & I6 & Exploratory \\
\hline Albers and Klaas-Wissing (2012) & S2 & I6 & Exploratory \\
\hline Czerny et al. (2016) & S2 & I6 & Experimental \\
\hline Klaas-Wissing and Albers (2010) & $\mathrm{S} 2$ & I7 & Exploratory \\
\hline Agrell et al. (2017) & S2 & I7 & Exploratory \\
\hline Ağralı et al. (2008) & S3 & $\mathrm{I} 3$ & Experimental \\
\hline Caplice (2007) & S3 & $\mathrm{I} 3$ & Exploratory \\
\hline Huang and Xu (2013) & S3 & $\mathrm{I} 3$ & Experimental \\
\hline Kuyzu et al. (2015) & S3 & $\mathrm{I} 3$ & Experimental \\
\hline van Duin et al. (2007) & S3 & $\mathrm{I} 3$ & Experimental \\
\hline $\mathrm{Xu}$ and Huang (2013) & S3 & $\mathrm{I} 3$ & Experimental \\
\hline $\mathrm{Xu}$ and Huang (2014) & S3 & I3 & Experimental \\
\hline $\mathrm{Xu}$ et al. (2016) & S3 & $\mathrm{I} 3$ & Experimental \\
\hline Gansterer et Hartl (2016) & S3 & I3 & Experimental \\
\hline Soysal et al. (2016) & S4 & I1 & Experimental \\
\hline Cruijssen et al. (2007a) & S4 & $\mathrm{I} 2$ & Experimental \\
\hline Adenso-Díaz et al. (2014a) & S4 & I2 & Experimental \\
\hline
\end{tabular}


Adenso-Díaz et al. (2014b) S4

Ergun et al. (2007a)

Ergun et al. (2007b)

Pérez-Bernabeu et al. (2015)

Kuyzu (2017)

Chabot et al. (2018)

Creemers et al. (2017)

Hezarkhani et al. (2015)

Yang et al. (2015)

Audy et al. (2011)

Audy et al. (2012a)

Lozano et al. (2013)

Özener and Ergun (2008)

Vanovermeire and Sörensen (2014a)

Vanovermeire and Sörensen (2014b)

Vanovermeire et al. (2014)

Yilmaz and Savasaneril (2012)

Li et al. (2016)

Defryn et al. (2016)

Ben Jouida et al. (2017)

Guajardo et al. (2016)

Frisk et al. (2010)

Cruijssen et al. (2010a)

Palhazi Cuervo et al. (2016)

Padilla Tinoco et al. (2017)

Gharehgozli et al. (2017)

Wang et al. (2015)

Cruijssen et al. (2007b)

Schmoltzi and Wallenburg (2011)

Cruijssen et al. (2010b)

Raue and Wallenburg (2013)

Schmoltzi and Wallenburg (2012)

Verstrepen et al. (2009)

Wallenburg and Raue (2011)

Leitner et al. (2011)

Pan et al. (2013)

Pan et al. (2014)

Ballot and Fontane (2010)

Hingley et al. (2011)

Mason et al. (2007)

Rodrigues et al. (2015)

Sarraj et al. (2014a)

Fazili et al. (2017)

Ben Mohamed et al. (2017)

Qiao et al. (2016)

Lin et al. (2014)

Montreuil (2011)

Pan et al. (2015)

Sarraj et al. (2014b)

Yang et al. (2017b)

Sallez et al. (2016)

Yang et al. (2017a)

Stadtler (2009)

Gansterer and Hartl (2018)

Nagarajan and Sošić (2008)

Guajardo and Rönnqvist (2016)

Cruijssen et al. (2007c)

Pomponi et al. (2015)

Audy et al. (2012b)

Brekalo et al. (2013)
General

General

General

General

General

General

General

General
Experimental

Experimental

Experimental

Experimental

Experimental

Experimental

Experimental

Experimental

Experimental

Experimental

Experimental

Experimental

Experimental

Experimental

Experimental

Exploratory

Experimental

Experimental

Experimental

Experimental

Experimental

Experimental

Experimental

Experimental

Experimental

Experimental

Exploratory

Exploratory

Exploratory

Exploratory

Exploratory

Exploratory

Exploratory

Exploratory

Exploratory

Exploratory

Exploratory

Exploratory

Exploratory

Exploratory

Exploratory

Experimental

Experimental

Experimental

Experimental

Experimental

Exploratory

Exploratory

Exploratory

Experimental

Exploratory

Experimental

Review

Review

Review

Review

Review

Exploratory

Exploratory

Exploratory 


\section{Table 2. Dual-axis classification of the papers reviewed}

Three categories of research methodology can be found from the survey. First, some experimental research uses mathematical models (such as optimisation, simulation, game theory) for quantitatively or qualitative study. Second, some research that are more exploratory deal with the exploration and definition of new concepts, the development of managerial models, case studies or interviews with logistics or industrial companies to identify the challenges and opportunities of HCT in the real industrial world. The third category contains literature reviews or survey focusing on reviews on HCT solutions or relevant issues.

Some papers provide general discussions on implementation issues but do not focus on one specific HCT solution and are thus classified herein as general papers (see Table 2). For example, Cruijssen et al. (2007c) reviewed the state-of-the-art of horizontal cooperation models and practical examples from trucking companies. Cheikhrouhou et al. (2010) proposed a multi-criteria model for evaluating the business benefits and the importance of partner selection. Nagarajan and Sošić (2008) and Guajardo and Rönnqvist (2016) reviewed the applications of cooperative game theory in HCT. Audy et al. (2012b), Brekalo et al. (2013), and Pomponi et al. (2015) studied management and governing issues in logistics collaboration to develop some management frameworks to improve the success of logistics collaboration. Stadtler (2009) and Gansterer and Hartl (2018) surveyed optimisation models in transport planning.

\section{Classification of HCT Solutions}

This section discusses one by one the definitions and collaboration schemes of the six classes of HCT solutions introduced previously.

\subsection{Single Carrier Collaboration (S1)}

Single carrier collaboration is a term used in Hernández et al. (2011) to describe an HCT solution for an autonomous and independent carrier who collaborates with one or more other carriers. It is a peer-to-peer bilateral collaboration between carriers who are motivated by at least three goals, i.e., reduce transport costs (Hernández et al., 2011, Buijs et al., 2016), acquire external capacity to serve excess requests (Hernández and Peeta, 2014), or improve services for the (same) client (Puettmann and Stadtler, 2010). Practical examples include collaboration between express carriers, for example, Fedex (in the US) and Chronopost (in France) collaborating to improve local delivery services and efficiency in both countries.

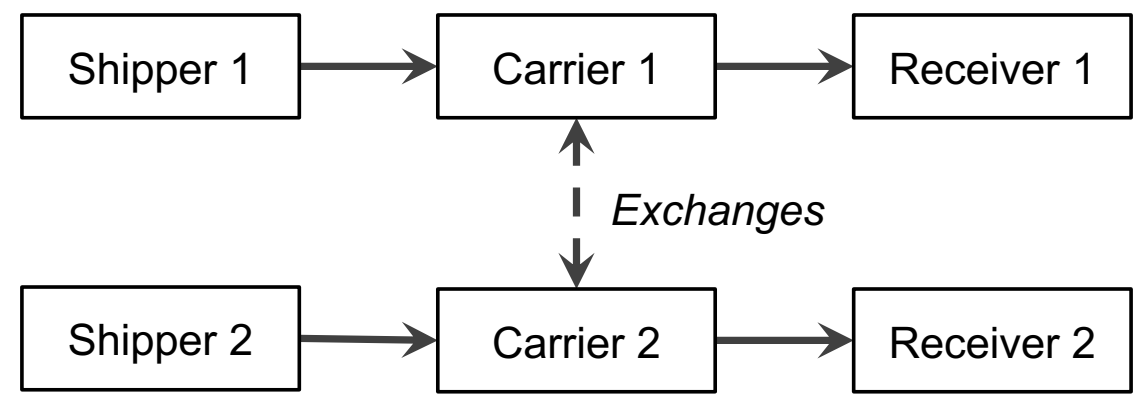

Figure 2. Single carrier collaboration scheme 
Figure 2 illustrates the single carrier collaboration scheme. For each SC, shippers (same to receivers) will procure transport services from a carrier to ship freight to a receiver. The two carriers serving different SC may exchange on hand requests in order to improve transport efficiency and thus profitability. Moreover, a carrier takes a request from another with the transport constraints given by the shipper and/or the receiver. The constraints can be lane, volume, lead time, delivery time windows, etc. The service undertaken must be maintained in the two SC after the exchange.

\subsection{Carrier Alliance and Coalition (S2)}

In contrast to bilateral exchange, a number of collaborating carriers may form a group for more stable and efficient collaboration. Transport requests can then be exchanged within the group in order to mutually optimise transport for a group of carriers, but not for a single carrier, as shown in Figure 3. This kind of group is generally called a carrier alliance or coalition. S2 differs mainly from S1 in organisation and management: S2 based on a multilateral alliance agreement, while S1 is based on a bilateral carrier-carrier agreement. The HCT solution is not new in transport industry, but it has been receiving attention in recent research.

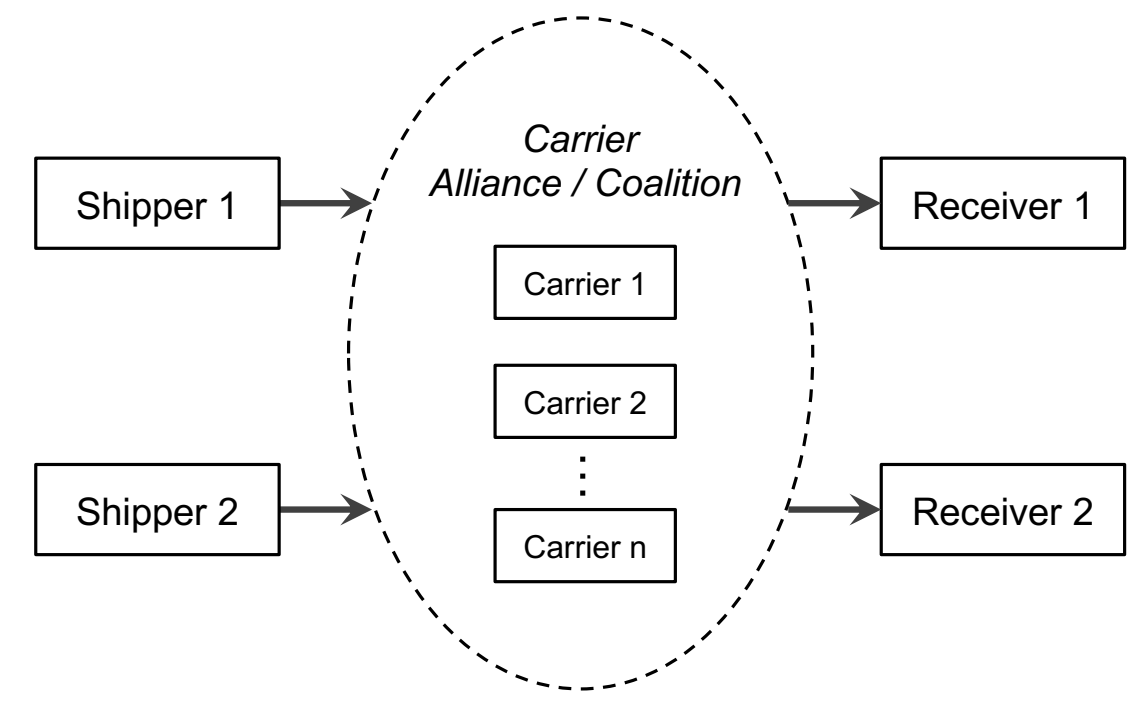

Figure 3. Carrier alliance or coalition collaboration scheme

Alliance and coalition are two distinct forms of organisation but sometimes misused interchangeably. In general, companies that are in an alliance collaborate with each other but operate as independent units, while companies in a coalition operate in a fully coordinated way and work as a single integrated company (Zhou et al., 2011), and is usually referred to as corporate mode for coalition and cooperative mode for alliance (Klaas-Wissing and Albers, 2010). The two forms also have different collaboration schemes for exchanging requests (Houghtalen et al., 2011, Verdonck et al., 2013). More specifically, carriers in an alliance may choose to outsource their low-profit transport requests that are available to other alliance partners or pick up appropriate requests from alliance partners to improve their vehicle fill rates (Dai and Chen, 2011, Li et al., 2015). However, carriers in coalitions will pool their on-hand requests and transport resources to establish globally optimal transport plans (Dai and Chen, 2012a, Dai and Chen, 2012b). In other words, an alliance is based on decentralised planning, while a coalition is based on centralised planning. As a result, a coalition normally achieves better global optimality for all partners than an alliance (Agarwal and Ergun, 2008, Agarwal and Ergun, 2010, Houghtalen et al., 2011, Zhou 
et al., 2011, Kuo and Miller-Hooks, 2012, Defryn and Sörensen, 2018, Defryn et al., 2017). In practice, an alliance is more suitable for large groups of trucking companies (e.g. ASTRE), while a coalition is better for small groups, as evidenced by the case study involving two real-life companies in Albers and Klaas-Wissing (2012).

\subsection{Transport Marketplace (S3)}

HCT can also be achieved through transport marketplaces (precisely speaking, it is a solution for cooperation at the operational level). A transport marketplace, also called freight marketplace or shipping marketplace, is a place where shippers (or receivers) procure transport services from carriers or LSPs (Xu and Huang, 2013, Huang and $\mathrm{Xu}, 2013)$. It can also be an online platform (Caplice, 2007, Huang and $\mathrm{Xu}, 2013$ ). Typically, in a transport marketplace, the buyers of a transport service are shippers (or receivers) and the sellers are carriers. Nevertheless, in some cases, carriers can be simultaneously buyers and sellers, for example, marketplaces that are open to carriers for exchanging requests (Caplice, 2007, Berger and Bierwirth, 2010, Dai and Chen, 2011). Marketplaces can thus be seen as collaborative transport marketplaces for carriers to achieve HCT, as shown in Figure 4.

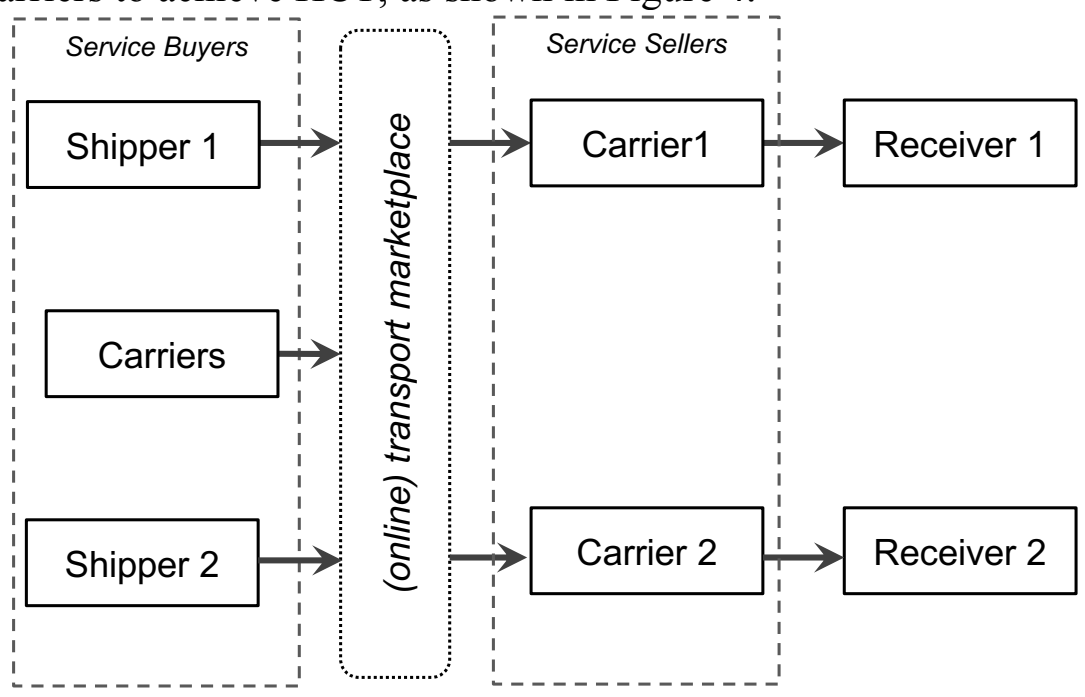

Figure 4. Carrier collaboration via transport marketplace

A marketplace collaboration scheme differs from solutions S1 and S2 in the openness and flexibility of the collaboration. A carrier can simply enter his request in the system without seeking long-term partners. Then, any carrier offering an attractive price can respond to the request via the system. No long-term contract or alliance agreement is required in the exchange, contrary to S1 and S2. The openness enhances the flexibility and the agility of HCT, which are particularly important for on-demand transport requests (spot markets) (Caplice, 2007). However, cost optimisation is opportunistic compared to $\mathrm{S} 1$ and $\mathrm{S} 2$, since it depends on the bid prices submitted by carriers. Auction mechanism has been popularly proposed to mitigate the loss of cost efficiency (see discussion in Section 5.3).

\subsection{Flow-controlling Entities Collaboration (S4)}

Further to collaboration between carriers, HCT may also arise between horizontal actors who have direct control over the flow of goods at SC level. The actors, including shippers (suppliers), LSP (3PL/4PL), and receivers (retailers) are called Flow-controlling Entities (FCE) in the literature (Pomponi et al., 2015, Cruijssen et al., 2007a). Take shipper as an example of FCE. Collaborating shippers can 
collectively and mutually define or revise logistics and transport constraints (e.g., lane, volume, lead time, delivery time windows), for the sake of transport synergy (Ergun et al., 2007b). This kind of solution is fundamentally different to carrier-based HCT solutions (S1, S2, and S3) since in the latter carriers are not allowed to modify transport constraints imposed by the shipper, thus limiting transport synergy (Vanovermeire et al., 2014). In particular, for shippers who have outsourced logistics and transport activities to LSP, they could ask their LSP to collaborate, or just use a common LSP (Soysal et al., 2018, Gharehgozli et al., 2017). We must clarify that the term LSP used here stands for 3PL/4PL that manage shipper's logistics tasks, but it does not include carriers who only execute transport tasks. The reason is that an LSP should be able to revise the shipper's logistics and transport constraints for establishing shipper collaboration.

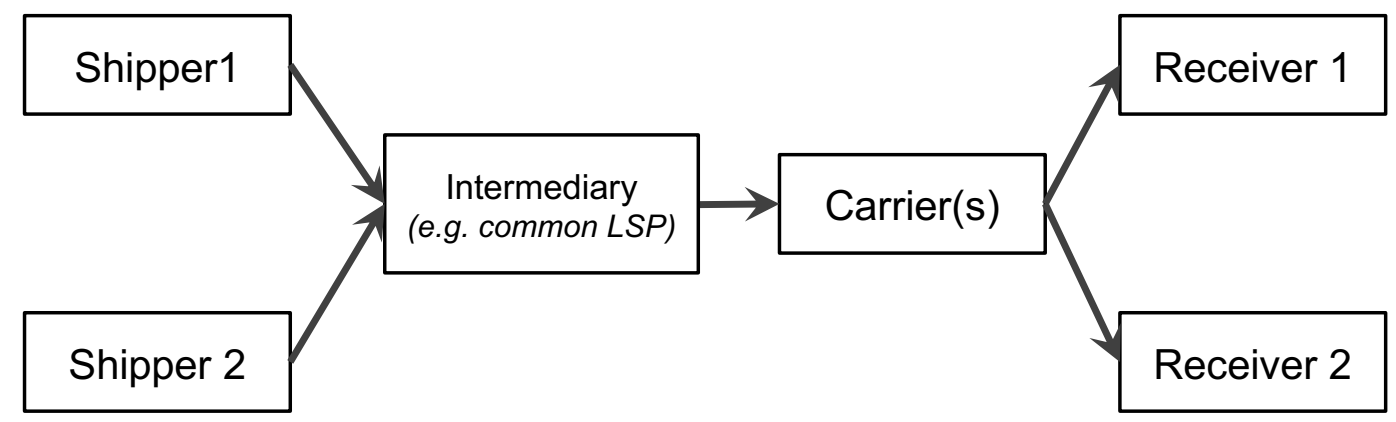

Figure 5. Flow-controlling entities collaboration scheme (shipper as example)

Figure 5 illustrates the collaboration scheme of two shippers via a common LSP or an intermediary (e.g. Amazon), as an example of FCE collaboration. In such a scheme, the LSP will establish mutual transport plans for the shippers and sends transport requests to carriers. It is called Joint route planning (JRP) in Cruijssen et al. (2007a), Cruijssen et al. (2007b), and Verstrepen et al. (2009). The authors argue that JRP works on the basis of collaboration between FCE, and between those who have a joint distribution centre or whose vehicle depots are located "sufficiently close" to each other.

\subsection{Logistics Pooling (S5)}

Logistics pooling, or supply chain pooling, can be described as a solution to exploit synergies between supply chains by combining vertical and horizontal collaboration (Mason et al., 2007, Rodrigues et al., 2015). Ballot and Fontane (2008), Pan et al. (2013) and Pan et al. (2014) further proposed a definition of pooling as a solution for co-designing and sharing a common logistics network by partners (suppliers, retailers, carriers, LSP, etc.) with a common objective. And the resources (warehouses, platforms, transport resources, etc.) are pooled and shared by the partners. According to this definition, S5 differs from S4 in that the former aims to coordinate all SC stakeholders and integrate their common interests into the solution in order to optimise and maximise transport synergy, while S4 only concerns horizontal flow controllers. In other words, S5 may outperform S4 in terms of transport synergy exploitation, but the organisation and management of S5 could be more complex and complicated. 


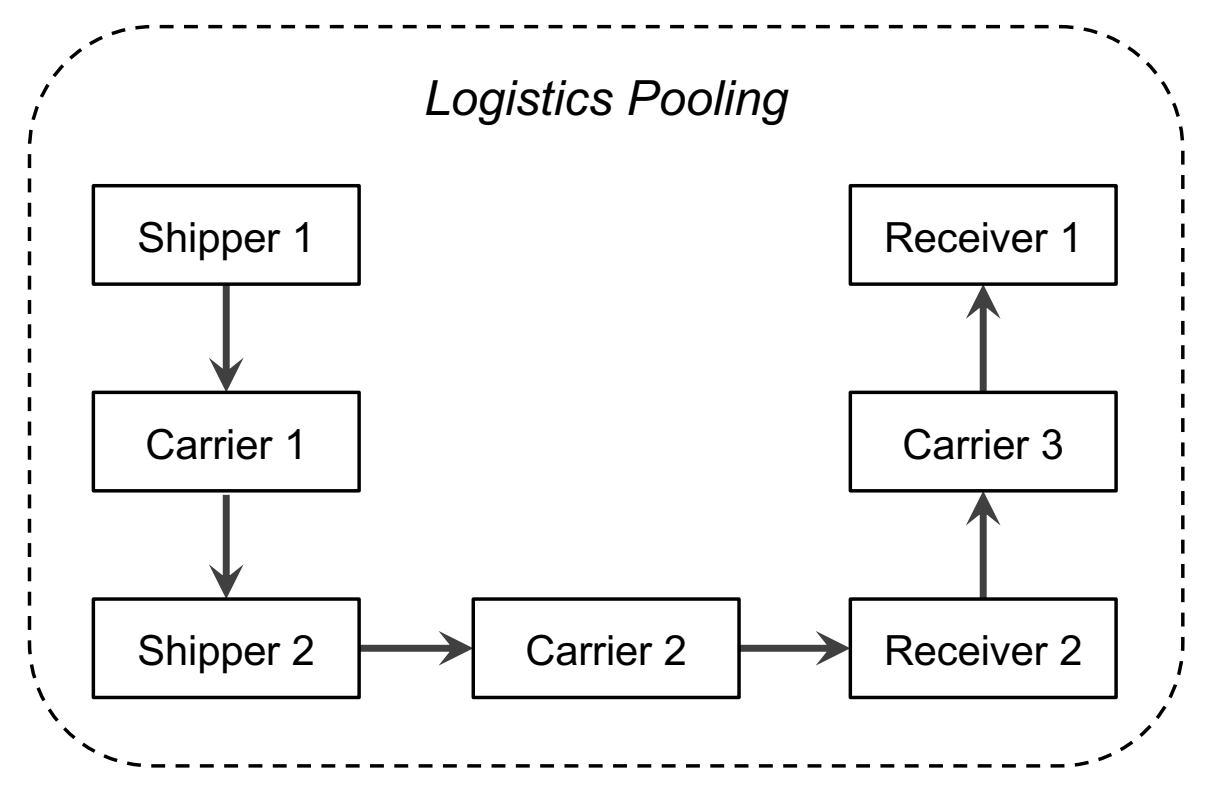

Figure 6. Logistics pooling scheme

Figure 6 illustrates an example of SC pooling adapted from Pan et al. (2013). Before pooling, shipper 1 and shipper 2 independently ship goods to both receiver 1 and receiver 2. After pooling, the shippers can share a warehouse (that of shipper 2, for example) to consolidate their flows to be dispatched; meanwhile, the receivers can also share a distribution centre (that of receiver 2, for example) to consolidate their flows to be received. In this way, both upstream and downstream flows are consolidated so that carrier 2 carries all the flows. The interests and constraints of all stakeholders (shippers, LSP, and receivers) should be considered when designing mutual transport plans. A practical example is the pooling case led by FM Logistic in France, which comprises 7 manufacturers, 6 retailers, and 10 LSP (Gapska and Rutkowski, 2009). Case studies can also be found in Ballot and Fontane (2010), Pan et al. (2013), and Pan et al. (2014) in the fast moving consumer goods (FMCG) sector, or in Hingley et al. (2011) in the grocery sector.

\subsection{Physical Internet (S6)}

The Physical Internet (PI) is an HCT solution that has been developed since 2010. It is proposed for the purpose of developing a shared, highly modularised, standardised, and interoperable collaborative transport network of which the aim is to interconnect currently independent transport networks, as a metaphor of the digital internet (Montreuil, 2011, Ballot et al., 2014, Sarraj et al., 2014b, Pan et al., 2017a, Fazili et al., 2017). It is also called "the network of independent logistics networks" in Ballot et al. (2014). Modularisation and standardisation of materials (physical, informational, and managerial) are key factors in the success of such a network, as they play a vital role in seamless interoperability between networks (Montreuil, 2011, Lin et al., 2014, Sallez et al., 2016). 


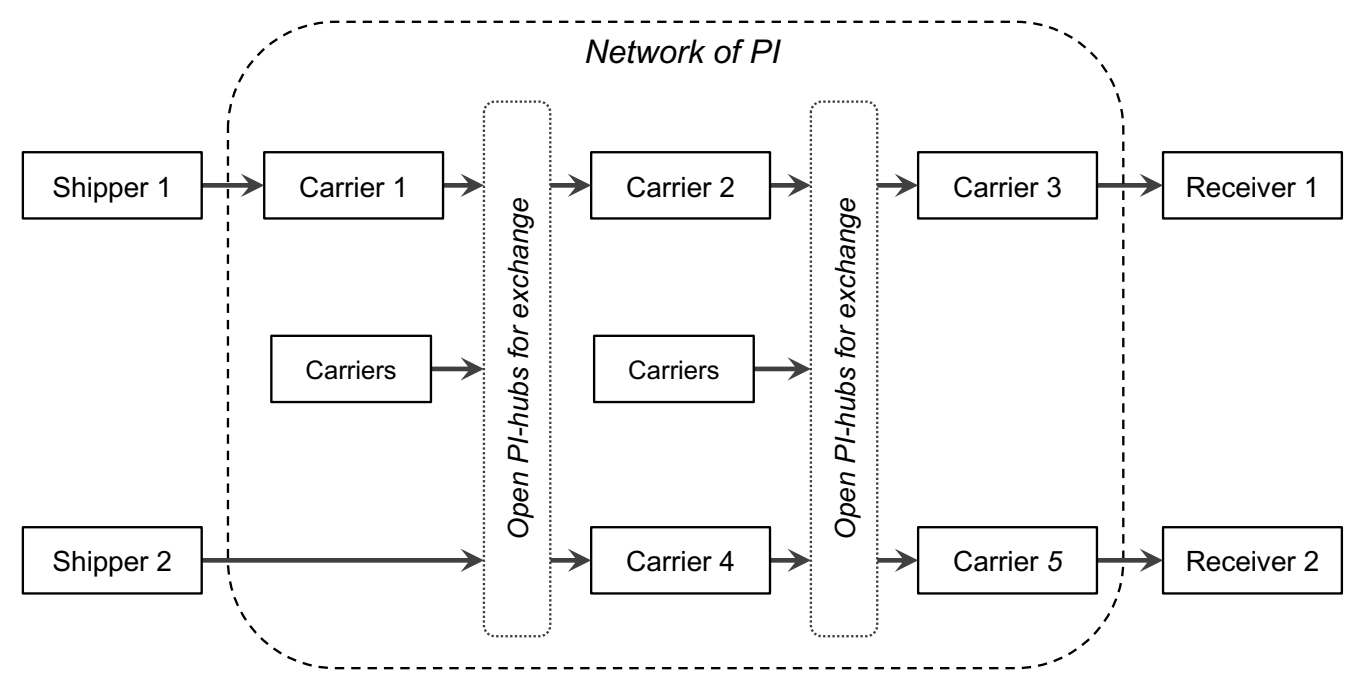

Figure 7. Physical Internet collaboration scheme

Figure 7 illustrates an example of PI. Within the PI network, carriers can exchange requests through an open PI-hub to optimise truck fill rates or reduce empty runs. It is similar to the way that data packets are routed via routers in the digital internet (packets and routers are respectively freight and PI-hubs in PI). In this way, a request can be reallocated to the most competitive carrier every time it arrives at a hub, and each reallocation is considered as a local optimisation. The particularity in PI is that transport is organised and optimised in a decentralised way. In other words, for a given request, its optimal route from the origin to the final destination will be updated every time it arrives at a PI-hub according to real-time, local information. To manage such decentralised systems, transport protocols and collaborative protocols are necessary for the level of service and global optimality of the network (Ballot et al., 2014, Xu, 2013). Besides, some studies have proven that such an interconnected and decentralised transport network can also help reduce inventory levels (Pan et al., 2015, Yang et al., 2017b, Yang et al., 2017a), or improve city logistics efficiency (Ben Mohamed et al., 2017).

\section{Classification of Implementation Issues}

This section discusses one by one the seven implementation issues raised by the HCT solutions.

\subsection{Collaborative network design (I1)}

In the context of HCT, collaborative network design aims at reorganising or designing a common, shared collaborative logistics and transport network for SC stakeholders. The objective of a collaborative network is to consolidate logistics flows from different SC. One example is to set up warehouse shared by multi-shippers, or distribution centre shared by multi-receivers. In terms of modelling, it is very similar to the traditional network design problem (Campbell et al., 2005) and has therefore been rarely studied alone in the literature. According to the papers devoted to the issue, optimisation approaches, especially Mixed integer linear programming, are the most common methods used to investigate the issue, for example, collaborative Huband-Spoke network design (Hernández et al., 2012, Wang et al., 2014a), pooled network design for multi-suppliers and multi-retailers (Pan et al., 2013), location of collaborative hubs for regional small and medium-sized food suppliers (Pan et al., 2014), and a collaborative network for the inventory routing problem (Soysal et al., 
2018). These experimental studies aimed to demonstrate the potential of collaborative networks in transport synergy.

\subsection{Transport planning optimisation (I2)}

Under a given transport network, collaborative transport planning optimisation issue consists of all collaborating actors (e.g., shippers, carriers) establishing optimal transport plans collectively and mutually. Two objectives are often considered in the optimisation, i.e., improve transport fill rate especially for less-than-truckload shipments (Dai and Chen, 2012a, Cruijssen et al., 2007a, Adenso-Díaz et al., 2014b), and reduce empty runs of repositioning especially for truckload shipments (Liu et al., 2010a, Liu et al., 2010b, Ergun et al., 2007b, Bailey et al., 2011, Adenso-Díaz et al., 2014a, Lin and Ng, 2012, Pérez-Bernabeu et al., 2015). The effects are called, respectively, economies of scale (Wang and Kopfer, 2015) and economies of scope (Özener et al., 2011) in transport.

Two modelling approaches are often used for collaborative transport planning: the collaborative vehicle routing problem (CVRP) and the collaborative lane covering problem (CLCP). CVRP is an extension of VRP from single to multiple carriers. Classic VRP aims to minimise the total cost (or time, distance, etc.) of delivering $n$ requests assigned to a single carrier, while CVRP aims to maximise the total profit of delivering $n$ requests assigned to $m$ collaborating carriers. More specifically, the cost of fulfilling a request can be different for each collaborating carrier, so it is possible to establish a mutual routing plan to maximise the total profit for all carriers. CVRP should also consider some constraints, such as carrier capacity (Wang et al., 2014a, Montoya-Torres et al., 2016, Fernández et al., 2016, Hernández et al., 2011, Hernández and Peeta, 2011, Wang et al., 2014b, Chabot et al., 2018, Fernández et al., 2018), time windows of requests (Caballini et al., 2016, Molenbruch et al., 2017), availability of information for planning (static, dynamic or real-time information) (Dai and Chen, 2012a, Wang and Kopfer, 2014, Hernández and Peeta, 2014, Wang and Kopfer, 2015, Dahl and Derigs, 2011, Zhang et al., 2017), or emissions (MuñozVillamizar et al., 2017). The second approach, CLCP, is often used in FCE collaboration (S4) (Kuyzu, 2017, Ergun et al., 2007a, Ergun et al., 2007b). Technically, CLCP aims to find a set of transport plans covering all lanes (from multishippers) such that the total cost to serve the lanes is minimised. The cost reduction may come from bundling, back-hauling, or round-trip (Creemers et al., 2017). As discussed in Kuyzu (2017), the main difference between CVRP and CLCP is that the former focuses on tour optimisation, while the latter focuses more on lane exchange optimisation without considering vehicle tours.

\subsection{Mechanism for exchanging requests (I3)}

This issue deals with incentives and methods to exchange requests. The issue is very important to study since it could be involved in all HCT solutions. Mechanism design is a popular approach. Two main mechanisms were studied in the literature: side payment and auction. Side payment refers to monetary transfer between two carriers when requests (or capacity) are exchanged (Özener et al., 2011, Agarwal and Ergun, 2008, Agarwal and Ergun, 2010). It is also called collaborative price in Zhou et al. (2011), or capacity exchange price in Houghtalen et al. (2011). Basically, it can be seen as the price fixed by a carrier for the extra-capacity he wants to sell. The crucial decision is fixing the right price with a dual objective: effectiveness to encourage carriers to exchange requests, and efficiency to reach an optimal exchange solution 
(Houghtalen et al., 2011). In other words, the price is leverage to optimise transport. Two main methods are proposed to solve the problem: the inverse optimisation method in Agarwal and Ergun (2008) and Houghtalen et al. (2011), and price sensitivity simulation in Zhou et al. (2011).

The auction mechanism is also proposed for exchanging requests. In this context, the auction can be seen as a transport procurement process where carriers submit (to the auctioneer) a price for a transport request placed by a shipper or other carrier. Then, the auctioneer will decide the winner for each request according to the prices submitted. The process concerns two main problems: the bidding price setting problem and the winner determination problem (WDP). The former consists of determining the optimal bidding price for a request (or for a bundle of requests), whereby the carrier's expected revenue is maximised (Ağralı et al., 2008, Dai et al., 2014, Kuyzu et al., 2015, Qiao et al., 2016, Gansterer and Hartl, 2016). The latter consists of assigning many requests to many bidding carriers in an optimal way, usually solved using linear programming (Xu and Huang, 2014, Berger and Bierwirth, 2010, Huang and $\mathrm{Xu}, 2013, \mathrm{Xu}$ et al., 2016, Xu and Huang, 2013, Dai and Chen, 2011, Chen, 2016, Kuo and Miller-Hooks, 2012, Lai et al., 2017). Moreover, auctions may have different mechanisms depending on the actual problem to be solved (see van Duin et al. (2007) and Verdonck et al. (2013) for a comparison of the mechanisms). The literature reveals that second price or double auction is effective and efficient to exchange requests; and combinatorial auction is efficient to exploit transport synergies in-between requests.

Compared to the side payment mechanism, the auction mechanism is more suitable for decentralised HCT solutions due to its real-time, local optimisation capability. That is why it has been widely studied in (online) freight marketplace, and also considered in single carrier collaboration and carrier coalition/alliance (Caplice, 2007). Nevertheless, the disadvantage is that the auction mechanism might not ensure global optimality for all carriers as a whole since it does not rely on centralised planning (Berger and Bierwirth, 2010).

\subsection{Gain sharing (I4)}

The gain sharing (or cost allocation) issue concerns how to fairly allocate the common gain (or cost) to collaborating players. Gainsharing is not new in economic theory but its application in HCT is particularly promising. Cooperative game theory is the dominant approach (see the two reviews by Nagarajan and Sošić (2008) and Guajardo and Rönnqvist (2016)). With the same goal that is to develop fair rules or models to allocate gain, the papers differ from each other in the constraints or criteria of fairness taken into account, for example additional desirable properties in collaboration (Özener and Ergun, 2008), satisfying the coalition budgetary balance (Yilmaz and Savasaneril, 2012), the player's stand-alone cost before collaboration (Audy et al., 2011, Padilla Tinoco et al., 2017) or bargaining power (Guajardo et al., 2016, Yang et al., 2015), the player's flow characteristics (Palhazi Cuervo et al., 2016) or flexibility in transport (Vanovermeire and Sörensen, 2014b, Vanovermeire et al., 2014), or the cost of unvisited customers in collaborative routing (Defryn et al., 2016). In particular, the Shapley Value based on the player's contribution to the gain is the model which most often proposed in the studies due to its validity and convenience of implementation (Dai and Chen, 2012b, Cruijssen et al., 2010a, Krajewska et al., 2008, Vanovermeire and Sörensen, 2014a). Some studies also used the Shapley Value to 
compare the proposed methods (Lozano et al., 2013, Frisk et al., 2010, Hezarkhani et al., 2015, Li et al., 2016, Verdonck et al., 2016).

The gain sharing problem can be extended to the coalition stability problem since the sharing scheme is crucial to coalition stability (Audy et al., 2012a). Most of the studies cited above only consider grand coalition including all players. However, in some cases, some players may be more interested in joining sub-coalitions that contain only a subset of players but provide higher profit for each (see the case in Cruijssen et al. (2010a)). Then, the problem is finding the most profitable and stable sub-coalitions, if there are any. This is called the coalition formation game (Audy et al., 2012a, Ben Jouida et al., 2017). The problem has received less attention in this survey.

Not all HCT solutions involve the gain sharing or coalition formation issues. These issues are implicated more in solutions that are usually employed within a coalition/alliance organisation, S1, S2, S4, and S5, for example. Other solutions like S3 and S6 are less concerned since they do not necessarily rely on this kind of organisation.

\subsection{Communications technology (I5)}

Previous studies have proven that information sharing is crucial to improve collaboration efficiency, see Berger and Bierwirth (2010) and Özener et al. (2011) for example. How partners effectively and efficiently communicate with others to share information becomes an issue and impediment of HCT (Cruijssen et al., 2007b). But surprisingly, in this survey we were able to find only two papers that focus on the issue of information communication technology (ICT). At carrier level, Buijs and Wortmann (2014) investigated how ICT can help carriers establish optimal transport plans in a dynamic way by sharing real-time information. They found that the practicability and performance of dynamic planning depend on the harmonisation of different IT applications used by collaborating carriers. At supply chain and network level, Wang et al. (2015) investigated how ICT employed between collaborating shippers can help reduce $\mathrm{CO}_{2}$ emissions from freight transport in the grocery retail industry in the UK. According to this case study, ICT solutions exist at transport and supply chain level, but there is a lack of ICT provision and usage at network level.

As sharing real-time information plays a vital role in HCT, it is foreseeable that ICT will attract more attention. This is particularly important for solutions at supply chain and network level, for example S4, S5, and S6, because monitoring, tracing, and tracking freight from end to end will be more complicated in such shared, open systems with multi-SC or network.

\subsection{Organisation (I6)}

Organisation issues examine how to build and organise HCT. They concern the organisation, motives, and organisational concepts (facilitators) of HCT. The organisation of each of the six HCT solutions has already been discussed in Section 4. Motives often include cost reduction, better service, and better competitiveness to protect market positioning (Cruijssen et al., 2007b). Shippers are mostly attracted by cost and service improvement. However, market-oriented motives, considering improving the quality of service to enhance the market share, are of primary importance for LPS (Cruijssen et al., 2010b, Schmoltzi and Wallenburg, 2011, 
Verstrepen et al., 2009). Recently, SC stakeholders also expected sustainability and resilience from HCT solutions (Montreuil, 2011, Yang et al., 2017b, Ballot and Fontane, 2010, Pérez-Bernabeu et al., 2015, Czerny et al., 2016).

Despite strong motives, HCT solutions may fail due to some organisational impediments (Cruijssen et al., 2007b, Rodrigues et al., 2015). To overcome the latter, some organisational concepts have been proposed. For carrier collaboration (S2 for example), a limited liability company (LLC) is usually formed to organise and manage an alliance (or a coalition) (Albers and Klaas-Wissing, 2012). LLC can be economically independent (owned by someone outside the alliance) or dependent (owned by the partners in the alliance). The former is more autocratic-members can either accept the board's decision or leave the alliance - while the latter is more democratic - members make strategic decisions together (see the study of two cases in Albers and Klaas-Wissing (2012)). For cross supply chain collaboration (S4 and S5 for example), orchestrator is a concept to be highlighted. A cross supply chain orchestrator can be considered as an impartial coordinator who manages and coordinates multiple supply chains to create horizontal collaboration and value (Zacharia et al., 2011). It can be a 3PL or 4PL managing multiple supply chains (Hingley et al., 2011, Rodrigues et al., 2015). It can also be a "trustee", adding the duty of allocating gain to patterns (see Vanovermeire and Sörensen (2014a), and the project Collaboration Concepts for CO-modality $\left(\mathrm{CO}^{3}\right)$ discussed in Rossi (2012)). Likewise, Kok et al. (2015) proposed the cross-chain collaboration centre (4C) concept that, concretely, is a control tower aimed at managing, executing, and controlling cross-chain logistics activities. Similar approach is also studied for urban logistics (Allen et al., 2017). An example is TRI-VIZOR located in Belgium, claimed as an cross supply chain orchestrator (Creemers et al., 2017). Another example is $C R C^{\circledR}$ Services located in France, which is a pooled cross-docking platform managed by an independent 4PL for multi-manufacturers and multi-distributors in the FMCG sector (CRC, 2016). More industrial examples can be found in Saenz et al. (2015).

\subsection{Management and Governance (I7)}

Management and governance issues deal with the question of how to manage and maintain an HCT solution. It includes business issues between collaborating companies, e.g., organisational culture, managers and employees' behaviour, conflict of interest. Management framework development and operational governance modes are the two main problems covered by the survey. A management framework for HCT can be considered as a stepwise framework to manage key decisions and influencing factors involved in HCT (Audy et al., 2012b, Brekalo et al., 2013, Leitner et al., 2011, Verstrepen et al., 2009). For example, a framework can involve three stages. The first stage concerns partner selection (Cheikhrouhou et al., 2010, Raue and Wallenburg, 2013) and developing trust between partners (Pomponi et al., 2015). The studies indicated that market position, common objectives and motives, structure, and similarity of flows influenced partner selection. The second stage is devoted to implementation, including defining the partner's responsibilities, leadership, and benefits (Audy et al., 2012b). Finally, the third stage concerns the long-term evolution and growth of the collaboration (Verstrepen et al., 2009).

Operational governance mode, which is sometimes part of the management framework (Verstrepen et al., 2009), relates to the selection of an adequate governance model for HCT. Governance mode plays a vital role in the efficacy of a 
collaboration (Schmoltzi and Wallenburg, 2012). There are two major governance models commonly used in practice: corporate and cooperative. These models are compared in Klaas-Wissing and Albers (2010) who indicate that with the former model, partners act as one single integrated company, while with the latter partners act as independent collaborating companies based on an alliance agreement (see also Agrell et al. (2017) for a practical example of the cooperative model). In both models, conflict management is one of the most prominent issues, see Wallenburg and Raue (2011) and Verstrepen et al. (2009), for example.

Besides, Virtual Enterprise (VE) is a noteworthy paradigm for investigating I6 and I7. An VE can be briefly descripted as "a temporary alliance of enterprises that come together to share skills or core competencies and resources in order to better respond to business opportunities, and whose cooperation is supported by computer networks" (Camarinha-Matos and Afsarmanesh, 2005). The definition implies that VE could be organisation and operation paradigm of interest for HCT implementation. The current VE and logistics related literature studies logistics network collaboration in general, particularly information management or partner selection (Gunasekaran et al., 2008, Dao et al., 2014, Hsu and Hsu, 2008); and it rarely focuses on horizontal collaboration and on transport. Obviously, the paradigm merits more attention in the next research on organisation and management models for HCT.

\section{Research Trends and Gaps}

This section surveys the state of the art of HCT according to the two axes introduced: solutions and implementation issues. Table 3 illustrates the number of studies in the survey per solution and per implementation issue.

\begin{tabular}{ccccccccc}
\hline \multirow{2}{*}{ HCT Solutions } & \multicolumn{7}{c}{ Implementation Issues } \\
\cline { 2 - 9 } & I1 & I2 & I3 & I4 & I5 & I6 & I7 & Total \\
\hline S1 & 0 & 3 & 0 & 0 & 0 & 1 & 0 & 4 \\
S2 & 2 & 19 & 13 & 3 & 1 & 3 & 2 & 43 \\
S3 & 0 & 0 & 9 & 0 & 0 & 0 & 0 & 9 \\
S4 & 1 & 9 & 0 & 19 & 1 & 3 & 5 & 38 \\
S5 & 2 & 0 & 0 & 0 & 0 & 4 & 0 & 6 \\
S6 & 0 & 3 & 1 & 0 & 0 & 7 & 0 & 11 \\
General & 0 & 2 & 0 & 2 & 0 & 1 & 4 & 9 \\
Total & 5 & 36 & 23 & 24 & 2 & 19 & 11 & 120 \\
\hline
\end{tabular}

Table 3. Number of studies per solution and per implementation issue in the survey

\subsection{HCT solutions}

With regard to HCT solutions, several remarks can be drawn from Table 3 and Section 4. Firstly, the spectrum of HCT solutions has been extended from carrier level (i.e. S1-Single carrier collaboration, S2-Carrier Alliance/Coalition, S3-Transport Marketplace) to supply chain level (i.e. S4-FCE collaboration and S5-Logistics pooling), and to supply network level (i.e. S6-Physical Internet). The main reason is that both carriers and other SC stakeholders are now interested in HCT. Specific solutions should be developed for each according to their own interests and convenience. For example, S1 and S3 would be adequate for big trucking companies who prefer to maintain their independence and autonomy with regard to transport organisation. However, for small or self-employed trucking companies, S2 would be a 
better solution, since it would provide much greater possibilities to exchange requests and thus to reduce the transport cost. S4 is proposed for flow controllers who have compatible flows and who are geographically close to each other, while S5 and S6 are not proposed for one specific SC stakeholder but for all those with common interests. For companies who are seeking opportunities in HCT, the current broad spectrum of HCT solutions can provide sufficient support to choose a solution.

Secondly, the number of papers per solution is aligned with the development of HCT (see Table 3). Over the past ten years, the focus of research has clearly been on S2 and S4, since both solutions were considered valuable for both researchers and practitioners. Apparently, they are also the most advanced and applied HCT solutions within the chosen time frame. In contrast, S1 and S3, which are not new, have received little attention for different reasons. S1 concerns bilateral collaboration between large companies. The organisation is therefore relatively simple and only two implementation issues have been studied: transport planning and lane exchange mechanism. For S3, the marketplace is not always considered as an HCT solution. Although there are a number of papers that have studied the auction theory in the transport marketplace, not all are included in the survey since they focus on flow controller-carrier rather than carrier-carrier relationships. This can be seen as a limitation of the survey. S5 and S6 are relatively young but are rapidly developing as most of the related papers were published after 2013. They could be the next hot trend in HCT research. In particular, S6 has been considered as the central European 20302050 vision for supply chain and logistics by the European technology platform ALICE (ALICE, 2018). A comprehensive research and innovation roadmap to attain the Physical Internet by 2050 is also proposed highlighting extensive research and industrial prospects.

\subsection{Implementation issues}

Regarding implementation issues, our first remark is that the most important and significant issues, from strategic level to operational level, have been covered by the literature surveyed. It reflects the maturity of horizontal collaboration in logistics and transport which has moved on from proof of concept to implementation. Experience with regard to implementation has also been discussed in some case studies (see Hingley et al. (2011), Buijs and Wortmann (2014), Rodrigues et al. (2015), for example). The scientific literature thus provides solid support for implementing HCT solutions.

Secondly, in the literature, the focus has been on the development of decision-making models, specifically for I2-Transport planning optimisation, I3-Mechanism for exchanging requests, and I4-Gain sharing, according to Table 3. Most of the studies concern experimental research using mathematical models. This can be explained by the operational requirements for the implementation of HCT solutions, and by the interests of researchers. Inversely, I1-Collaborative network design has been studied a lot less in the context of HCT since it is mathematically extremely close to the classical network design problem.

Thirdly, we were very surprised by the fact that only two studies were devoted to I5Communications technology considering the importance of information exchange in HCT solutions. It could be due to the scope of the survey that is limited to academic journals and studies focusing on transport. However, it is reasonable to expect more 
research on this issue, particularly for solutions based on real-time decisions, such as S3 and S6.

Finally, from a practical point of view, management and governance issue (I7) has gained insufficient attention. Currently, this issue has only been considered for S2 and S4, and only two papers were devoted to S2. More particularly, for the more recent solutions S5 and S6, the development of management and governance operating models has never been investigated. As the latter are at network level, the paradigm of virtual enterprise could be a significant research direction. Besides, the survey reveals also the lack of study regarding legal issues. For example, from society's standpoint, horizontal collaboration between dominating actors would eventually result in cartels in the industry. Policy makers as well as companies should beware of the consequence of HCT. These issues should be further investigated for the practical and societal implications.

\subsection{Practical application}

Logistics parties who wish to embark on HCT may acquire instructive information from the survey results. From company point of view, they should first consider their position in the SC and the scope of HCT to be achieved. Accordingly, the 6 HCT solutions can be categorised into three levels of scope: S1, S2 and S3 at carrier level, S4 and S5 at SC level, and S6 at supply network level. It means that HCT solutions can have, respectively, only carrier perspective, FCE perspective, or all stakeholders' perspective.

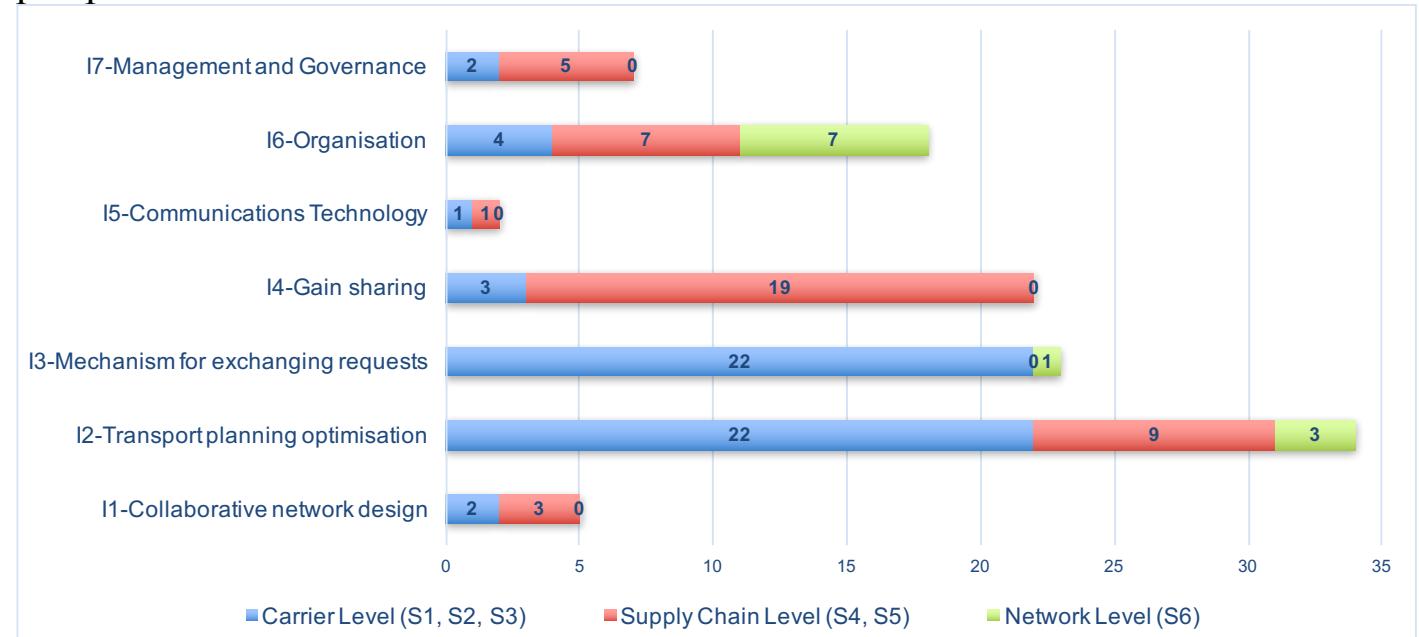

Figure 8. Contributions to implementation issues according to different HCT perspectives (the number of papers according to Table 2 without the category of general paper)

HCT solutions can be achieved from different perspectives so that implementation issues also vary according to different perspectives. According to Figure 8, it is obvious that transport planning and mechanism for exchanging requests are the two major issues for HCT at carrier level, while gain sharing almost only for HCT at SC level, and organisation issue equally important for HCT at SC and network level. More precisely, from practical perspectives, collaborating carriers should focus more on how to exchange requests and how to plan mutual transport, for which a massive theoretical support can be found in the literature. Collaborating flow controllers should pay more attention on gain sharing and organisation models and they can find an adequate literature addressing the issues. However, HCT at network level is still 
developing for practicability and more researches should be further done. The results imply that, before embarking on HCT, companies must consider their position in the SC, relationship with vertical or horizontal partners, their ability and flexibility for collaboration, and the maturity of HCT solution to implement.

\section{Further Research Prospects}

This part discusses several prospective lines of research derived from the survey but not limited to the solutions and implementation issues discussed. Firstly, further investigation is necessary to compare and contrast centralised and decentralised organisation for HCT. Klaas-Wissing and Albers (2010) gave an example comparing carrier alliance with coalition. However, current solutions are all based on centralised organisation at SC level (S4 and S5) and decentralised organisation at network level (S6). These solutions have not been compared. It is certain that centralised organisation may offer globally optimal solutions for all collaborating companies, but the companies may lose some of their independence and flexibility (Li et al., 2015). Moreover, significant change by any collaborator (e.g., flow, market size) would also destroy the existing collaboration (Rodrigues et al., 2015). In contrast, decentralised organisation offers greater independence and flexibility for collaborators, but not necessarily global optimality. Knowing that companies are looking not only for efficiency but also flexibility and dynamics in HCT solutions (Saenz et al., 2015), the possibility of developing a hybrid organisation model remains a research topic. Furthermore, management and governance operating models for decentralised organisation solutions also merit further investigation.

Secondly, developing real-time information communication processes is becoming urgent. Real-time communication is doubly important for HCT. Firstly, it enables real-time information sharing to make real-time decisions involving cross chain collaborators (truck sharing, routing optimisation, actual lead time, etc.). Secondly, it enhances real-time traceability and visibility of freight in a collaborative transport network. Thanks to modern technologies such as Internet of Things and RFID, it is easier to acquire real-time information related to logistics and transport. Nevertheless, information exchange still relies mostly on some traditional means such as e-mails or telephone calls, which seem inadequate to satisfy real-time communication. One solution is to interconnect the heterogeneous (cross chain) information systems via collaborative digital platforms with standardised API (application programming interface) and EDI (Electronic Data Interchange) messages. System architecture and process standardisation then become research problems. Furthermore, the subject can be extended to data governance and privacy, whose aim is to effectively and efficiently share real-time information. Finally, this research direction also towards the future scenario of logistics organisation that is open, intelligent, decentralised and self-organising (Pan et al., 2017b).

Thirdly, evaluation criteria and metrics for HCT solutions need to be enhanced in view of sustainability. In the survey, the main performance criterion of HCT solutions was economic, i.e., the reduction of logistics and transport costs. Only a few studies considered the environmental aspect $\left(\mathrm{CO}_{2}\right.$ emissions), and even fewer considered the social aspects. The assessment of HCT solutions is biased towards a single (economic) criterion, as also evidenced by the case study in Keseru et al. (2016). Due to this bias, the advantages of HCT might be underestimated and the disadvantages 
ignored. To improve reporting on the sustainability performance of HCT, accurate and comprehensive logistics metrics are necessary for further investigation.

Fourthly, not many studies focus on horizontal collaboration for intermodal transport, with only a few of the papers reviewed being devoted to this issue (see Puettmann and Stadtler (2010), Kuo and Miller-Hooks (2012), Pan et al. (2013) and Sarraj et al. (2014a)). This line of research should be enhanced for the sake of sustainability in logistics. The studies have proven that, for inland transport, high-volume modes of transport (like railways or waterways) are environmentally friendly, but are only costeffective with high-volume flows. Companies (shippers or receivers) may collaborate to consolidate flows by sharing means of transport. But collaborative planning could be long and complex due to booking means of transport in advance and lack of flexibility. More effective planning methods are necessary to overcome this impediment. Indeed, the problem relates to a current trend in supply chain and transport called synchromodality. The concept emphasises ad-hoc modal shifts (to more effective or efficient means of transport), even during execution of the transport plan (Kok et al., 2015). In this context, it is predictable that HCT and synchromodality play complementary roles in logistics sustainability.

Fifthly, HCT solutions for urban freight transport are appealing. Along with the development of e-commerce and home deliveries, urban freight transport has been rapidly increasing along with sustainable problems. As has been proven, HCT could be an effective and efficient approach to reduce the negative externalities of freight transport in cities. Currently, only few studies are looking into the issue. It should be emphasised that urban freight transport is much closer to our daily life in the city, and, thus, specific HCT solutions for urban freight transport should be developed for sustainability.

\section{Conclusion}

This paper provides a comprehensive literature review of horizontal collaborative transport (HCT) solutions based on 120 studies published between 2007 and 2017. It is worth noting that some papers may be missed, due to the scope of the survey that is limited to academic journals and studies focusing on horizontal collaboration and transport. A survey framework has been proposed under which the studies were classified according to two axes: HCT solutions and implementation issues. This framework can be used efficiently by researchers in HCT to position their work and their future research, as well as by practitioners to implement HCT solutions. This study has also set out some significant findings regarding emerging lines of research and gaps in the literature and provides some prospective lines of research. From industrial perspectives, the study successfully provides the guidelines to logistics stakeholders who wish to embark on HCT, which help them choose which HCT solution to implement as well as anticipate the implementation difficulties.

\section{References}

Adenso-Díaz, B., Lozano, S., Garcia-Carbajal, S. \& Smith-Miles, K. (2014a). "Assessing partnership savings in horizontal cooperation by planning linked deliveries". Transportation Research Part A: Policy and Practice, 66, 268-279. 10.1016/j.tra.2014.05.013 
Adenso-Díaz, B., Lozano, S. \& Moreno, P. (2014b). "Analysis of the synergies of merging multi-company transportation needs". Transportmetrica A: Transport Science, 10, 533-547. $10.1080 / 23249935.2013 .797518$

Agarwal, R. \& Ergun, Ö. (2008). "Mechanism design for a multicommodity flow game in service network alliances". Operations Research Letters, 36, 520-524

Agarwal, R. \& Ergun, Ö. (2010). "Network Design and Allocation Mechanisms for Carrier Alliances in Liner Shipping". Operations Research, 58, 1726-1742. 10.1287/opre.1100.0848

Ağral, S., Tan, B. \& Karaesmen, F. (2008). "Modeling and analysis of an auction-based logistics market". European Journal of Operational Research, 191, 272-294. http://dx.doi.org/10.1016/j.ejor.2007.08.018

Agrell, P. J., Lundin, J. \& Norrman, A. (2017). "Supply Chain Management: Horizontal carrier coordination through cooperative governance structures". International Journal of Production Economics, 194, 59-72. http://dx.doi.org/10.1016/j.ijpe.2016.10.025

Albers, S. \& Klaas-Wissing, T. (2012). "Organisation of multilateral LTL alliances". International Journal of Logistics Research and Applications, 15, 181-198. $10.1080 / 13675567.2012 .709836$

ALICE. 2018. European technology platform for logistics [Online].

Allen, J., Bektaş, T., Cherrett, T., Friday, A., McLeod, F., Piecyk, M., Piotrowska, M. \& Austwick, M. Z. (2017). "Enabling a Freight Traffic Controller for Collaborative Multidrop Urban Logistics". Transportation Research Record: Journal of the Transportation Research Board, 2609, 77-84. 10.3141/2609-09

ASTRE. 2016. ASTRE - Association des transporteurs européens [Online]. Available: http://www.astre.fr/en/.

Audy, J.-F., D'Amours, S. \& Rönnqvist, M. (2012a). "An empirical study on coalition formation and cost/savings allocation". International Journal of Production Economics, 136, $13-27$

Audy, J.-F., D'Amours, S. \& Rousseau, L.-M. (2011). "Cost allocation in the establishment of a collaborative transportation agreementan application in the furniture industry". Journal of the Operational Research Society, 62, 960-970. http://dx.doi.org/10.1057/jors.2010.53

Audy, J. F., Lehoux, N., D'Amours, S. \& Rönnqvist, M. (2012b). "A framework for an efficient implementation of logistics collaborations". International transactions in operational research, 19, 633-657

Bailey, E., Unnikrishnan, A. \& Lin, D.-Y. (2011). "Models for minimizing backhaul costs through freight collaboration". Transportation Research Record: Journal of the Transportation Research Board, 51-60

Ballot, E. \& Fontane, F. 2008. Reducing greenhouse gas emissions through the collaboration of supply chains: lessons from French retail chains. International Conference on Information Systems, Logistics and Supply Chain Conference. Madison, Wisconsin.

Ballot, E. \& Fontane, F. (2010). "Reducing transportation CO2 emissions through pooling of supply networks: perspectives from a case study in French retail chains". Production Planning \& Control, 21, 640 - 650

Ballot, E., Montreuil, B. \& Meller, R. (2014). The Physical Internet: The Network of Logistics Networks, Paris, France, La documentation Française.

Barratt, M. (2004). "Understanding the meaning of collaboration in the supply chain". Supply Chain Management: an international journal, 9, 30-42 
Ben Jouida, S., Krichen, S. \& Klibi, W. (2017). "Coalition-formation problem for sourcing contract design in supply networks". European Journal of Operational Research, 257, 539558. http://dx.doi.org/10.1016/j.ejor.2016.07.040

Ben Mohamed, I., Klibi, W., Labarthe, O., Deschamps, J.-C. \& Babai, M. Z. (2017). "Modelling and solution approaches for the interconnected city logistics". International Journal of Production Research, 55, 2664-2684. 10.1080/00207543.2016.1267412

Berger, S. \& Bierwirth, C. (2010). "Solutions to the request reassignment problem in collaborative carrier networks". Transportation Research Part E: Logistics and Transportation Review, 46, 627-638

Brekalo, L., Albers, S. \& Delfmann, W. (2013). "Logistics alliance management capabilities: where are they?". International Journal of Physical Distribution \& Logistics Management, 43, 529-543. doi:10.1108/IJPDLM-06-2012-0194

Buijs, P., Alvarez, J. A. L., Veenstra, M. \& Roodbergen, K. J. (2016). "Improved Collaborative Transport Planning at Dutch Logistics Service Provider Fritom". Interfaces, 46, 119-132. 10.1287/inte.2015.0838

Buijs, P. \& Wortmann, J. C. (2014). "Joint operational decision-making in collaborative transportation networks: the role of IT". Supply Chain Management: An International Journal, 19, 200-210. doi:10.1108/SCM-08-2013-0298

Caballini, C., Sacone, S. \& Saeednia, M. (2016). "Cooperation among truck carriers in seaport containerized transportation". Transportation Research Part E: Logistics and Transportation Review, 93, 38-56. http://dx.doi.org/10.1016/j.tre.2016.05.007

Camarinha-Matos, L. M. \& Afsarmanesh, H. (2005). "Collaborative networks: a new scientific discipline". Journal of Intelligent Manufacturing, 16, 439-452. 10.1007/s10845005-1656-3

Campbell, J. F., Ernst, A. T. \& Krishnamoorthy, M. (2005). "Hub Arc Location Problems: Part I: Introduction and Results". Management Science, 51, 1540-1555

Caplice, C. (2007). "Electronic Markets for Truckload Transportation". Production and Operations Management, 16, 423-436. 10.1111/j.1937-5956.2007.tb00270.x

Chabot, T., Bouchard, F., Legault-Michaud, A., Renaud, J. \& Coelho, L. C. (2018). "Service level, cost and environmental optimization of collaborative transportation". Transportation Research Part E: Logistics and Transportation Review, 110, 1-14. https://doi.org/10.1016/j.tre.2017.11.008

Cheikhrouhou, N., Piot, G. \& Pouly, M. (2010). "A multi-criteria model for the evaluation of business benefits in horizontal collaborative networks". Journal of Intelligent Manufacturing, 21, 301-309. 10.1007/s10845-008-0181-6

Chen, H. (2016). "Combinatorial clock-proxy exchange for carrier collaboration in less than truck load transportation". Transportation Research Part E: Logistics and Transportation Review, 91, 152-172. http://dx.doi.org/10.1016/j.tre.2016.04.008

CO3. 2014. Test Cases in practice [Online]. Available: http://www.co3-project.eu/test-casesin-practice/.

CRC. 2016. CRC - Collaborative Routing Centre [Online]. Available: http://www.crcservices.com/en.

Creemers, S., Woumans, G., Boute, R. \& Beliën, J. (2017). "Tri-Vizor Uses an Efficient Algorithm to Identify Collaborative Shipping Opportunities". Interfaces, 47, 244-259. 10.1287/inte.2016.0878

Cruijssen, F. 2006. Horizontal cooperation in transport and logistics. Ph. D, Tilburg University. 
Cruijssen, F., Borm, P., Fleuren, H. \& Hamers, H. (2010a). "Supplier-initiated outsourcing: A methodology to exploit synergy in transportation". European Journal of Operational Research, 207, 763-774

Cruijssen, F., Bräysy, O., Dullaert, W., Fleuren, H. \& Salomon, M. (2007a). "Joint route planning under varying market conditions". International Journal of Physical Distribution \& Logistics Management, 37, 287-304

Cruijssen, F., Cools, M. \& Dullaert, W. (2007b). "Horizontal cooperation in logistics: Opportunities and impediments". Transportation Research Part E: Logistics and Transportation Review, 43, 129-142

Cruijssen, F., Dullaert, W. \& Fleuren, H. (2007c). "Horizontal Cooperation in Transport and Logistics: A Literature Review". Transportation Journal, 46, 22-39. 10.2307/20713677

Cruijssen, F., Dullaert, W. \& Joro, T. (2010b). "Freight transportation efficiency through horizontal cooperation in Flanders". International Journal of Logistics Research and Applications, 13, 161-178

Czerny, A. I., van den Berg, V. A. C. \& Verhoef, E. T. (2016). "Carrier collaboration with endogenous fleets and load factors when networks are complementary". Transportation Research Part B: Methodological, 94, 285-297. http://dx.doi.org/10.1016/j.trb.2016.09.005

Dahl, S. \& Derigs, U. (2011). "Cooperative planning in express carrier networks - An empirical study on the effectiveness of a real-time Decision Support System". Decision Support Systems, 51, 620-626. http://dx.doi.org/10.1016/j.dss.2011.02.018

Dai, B. \& Chen, H. (2011). "A multi-agent and auction-based framework and approach for carrier collaboration". Logistics Research, 3, 101-120. 10.1007/s12159-011-0046-9

Dai, B. \& Chen, H. (2012a). "Mathematical model and solution approach for carriers' collaborative transportation planning in less than truckload transportation". International Journal of Advanced Operations Management, 4, 62-84

Dai, B. \& Chen, H. (2012b). "Profit allocation mechanisms for carrier collaboration in pickup and delivery service". Computers \& Industrial Engineering, 62, 633-643. http://dx.doi.org/10.1016/j.cie.2011.11.029

Dai, B., Chen, H. \& Yang, G. (2014). "Price-setting based combinatorial auction approach for carrier collaboration with pickup and delivery requests". Operational Research, 14, 361-386

Dao, S. D., Abhary, K. \& Marian, R. (2014). "Optimisation of partner selection and collaborative transportation scheduling in Virtual Enterprises using GA". Expert Systems with Applications, 41, 6701-6717. 10.1016/j.eswa.2014.04.030

Defryn, C. \& Sörensen, K. (2018). "Multi-objective optimisation models for the travelling salesman problem with horizontal cooperation". European Journal of Operational Research, 267, 891-903. https://doi.org/10.1016/j.ejor.2017.12.028

Defryn, C., Sörensen, K. \& Cornelissens, T. (2016). "The selective vehicle routing problem in a collaborative environment". European Journal of Operational Research, 250, 400-411. http://dx.doi.org/10.1016/j.ejor.2015.09.059

Defryn, C., Sörensen, K. \& Dullaert, W. (2017). "Integrating partner objectives in horizontal logistics optimisation models". Omega, (in press). https://doi.org/10.1016/j.omega.2017.11.008

Durach, C. F., Kembro, J. \& Wieland, A. (2017). "A new paradigm for systematic literature reviews in supply chain management". Journal of Supply Chain Management, 53. $10.1111 / \mathrm{jscm} .12145$

Ergun, Ö., Kuyzu, G. \& Savelsbergh, M. (2007a). "Reducing Truckload Transportation Costs Through Collaboration". Transportation Science, 41, 206-221 
Ergun, Ö., Kuyzu, G. \& Savelsbergh, M. (2007b). "Shipper collaboration". Computers \& Operations Research, 34, 1551-1560

Fazili, M., Venkatadri, U., Cyrus, P. \& Tajbakhsh, M. (2017). "Physical Internet, conventional and hybrid logistic systems: a routing optimisation-based comparison using the Eastern Canada road network case study". International Journal of Production Research, 55, 2703-2730. 10.1080/00207543.2017.1285075

Fernández, E., Fontana, D. \& Speranza, M. G. (2016). "On the Collaboration Uncapacitated Arc Routing Problem". Computers \& Operations Research, 67, 120-131. http://dx.doi.org/10.1016/j.cor.2015.10.001

Fernández, E., Roca-Riu, M. \& Speranza, M. G. (2018). "The Shared Customer Collaboration Vehicle Routing Problem". European Journal of Operational Research, 265, 1078-1093. https://doi.org/10.1016/j.ejor.2017.08.051

Frisk, M., Göthe-Lundgren, M., Jörnsten, K. \& Rönnqvist, M. (2010). "Cost allocation in collaborative forest transportation". European Journal of Operational Research, 205, 448-458

Gansterer, M. \& Hartl, R. F. (2016). "Request evaluation strategies for carriers in auctionbased collaborations". OR Spectrum, 38, 3-23. 10.1007/s00291-015-0411-1

Gansterer, M. \& Hartl, R. F. (2018). "Collaborative vehicle routing: A survey". European Journal of Operational Research, 268, 1-12. https://doi.org/10.1016/j.ejor.2017.10.023

Gapska, K. \& Rutkowski, K. 2009. Pooling in the retail FMCG sector - the case study of FM Logistic. Bruxelles: European Commission.

Gharehgozli, A. H., de Koster, R. \& Jansen, R. (2017). "Collaborative solutions for inter terminal transport". International Journal of Production Research, 55, 6527-6546. $10.1080 / 00207543.2016 .1262564$

Goldsby, T. J., Iyengar, D. \& Rao, S. (2014). The Definitive Guide to Transportation: Principles, Strategies, and Decisions for the Effective Flow of Goods and Services (Council of Supply Chain Management Professionals) Upper Saddle River, New Jersey, Pearson FT Press.

Guajardo, M., Jörnsten, K. \& Rönnqvist, M. (2016). "Constructive and blocking power in collaborative transportation". OR Spectrum, 38, 25-50. 10.1007/s00291-015-0413-z

Guajardo, M. \& Rönnqvist, M. (2016). "A review on cost allocation methods in collaborative transportation". International Transactions in Operational Research, 23, 371-392. 10.1111/itor.12205

Gunasekaran, A., Lai, K. \& Edwincheng, T. (2008). "Responsive supply chain: A competitive strategy in a networked economy". Omega, 36, 549-564. 10.1016/j.omega.2006.12.002

Hernández, S. \& Peeta, S. (2011). "Centralized Time-Dependent Multiple-Carrier Collaboration Problem for Less-Than-Truckload Carriers". Transportation Research Record: Journal of the Transportation Research Board, 26-34

Hernández, S. \& Peeta, S. (2014). "A carrier collaboration problem for less-than-truckload carriers: characteristics and carrier collaboration model". Transportmetrica A: Transport Science, 10, 327-349. 10.1080/23249935.2013.766279

Hernández, S., Peeta, S. \& Kalafatas, G. (2011). "A less-than-truckload carrier collaboration planning problem under dynamic capacities". Transportation Research Part E: Logistics and Transportation Review, 47, 933-946. http://dx.doi.org/10.1016/j.tre.2011.03.001

Hernández, S., Unnikrishnan, A. \& Awale, S. (2012). "Centralized Carrier Collaboration Multihub Location Problem for Less-Than-Truckload Industry: Hybrid Hub-and-Spoke Network". Transportation Research Record: Journal of the Transportation Research Board, 20-28 
Hezarkhani, B., Slikker, M. \& Van Woensel, T. (2015). "A competitive solution for cooperative truckload delivery". OR Spectrum, 1-30. 10.1007/s00291-015-0394-y

Hingley, M., Lindgreen, A., Grant, D. B. \& Kane, C. (2011). "Using fourth-party logistics management to improve horizontal collaboration among grocery retailers". Supply Chain Management: An International Journal, 16, 316-327. doi:10.1108/13598541111155839

Houghtalen, L., Ergun, Ö. \& Sokol, J. (2011). "Designing mechanisms for the management of carrier alliances". Transportation Science, 45, 465-482

Hsu, H.-P. \& Hsu, H.-M. (2008). "Systematic modeling and implementation of a resource planning system for virtual enterprise by Predicate/Transition net". Expert Systems with Applications, 35, 1841-1857. 10.1016/j.eswa.2007.08.082

Huang, G. Q. \& Xu, S. X. (2013). "Truthful multi-unit transportation procurement auctions for logistics e-marketplaces". Transportation Research Part B: Methodological, 47, 127-148. http://dx.doi.org/10.1016/j.trb.2012.10.002

Keseru, I., Bulckaen, J., Macharis, C. \& de Kruijf, J. (2016). "Sustainable Consensus? The NISTO Evaluation Framework to Appraise Sustainability and Stakeholder Preferences for Mobility Projects". Transportation Research Procedia, 14, 906-915. http://dx.doi.org/10.1016/j.trpro.2016.05.070

Klaas-Wissing, T. \& Albers, S. (2010). "Cooperative versus corporate governance of LTL networks". International Journal of Logistics Research and Applications, 13, 493-506

Kok, T. d., Dalen, J. v. \& Hillegersberg, J. v. (2015). Cross-chain collaboration in the fast moving consumer goods supply chain, Eindhoven, Rotterdam, University of Eindhoven.

Krajewska, M. A., Kopfer, H., Laporte, G., Ropke, S. \& Zaccour, G. (2008). "Horizontal cooperation among freight carriers: request allocation and profit sharing". Journal of the Operational Research Society, 59, 1483-1491

Kuo, A. \& Miller-Hooks, E. (2012). "Developing Responsive Rail Services through collaboration". Transportation Research Part B: Methodological, 46, 424-439. http://dx.doi.org/10.1016/j.trb.2011.10.009

Kuyzu, G. (2017). "Lane covering with partner bounds in collaborative truckload transportation procurement". Computers \& Operations Research, 77, 32-43. http://dx.doi.org/10.1016/j.cor.2016.07.018

Kuyzu, G., Akyol, Ç. G., Ergun, Ö. \& Savelsbergh, M. (2015). "Bid price optimization for truckload carriers in simultaneous transportation procurement auctions". Transportation Research Part B: Methodological, 73, 34-58. http://dx.doi.org/10.1016/j.trb.2014.11.012

Lai, M., Cai, X. \& Hu, Q. (2017). "An iterative auction for carrier collaboration in truckload pickup and delivery". Transportation Research Part E: Logistics and Transportation Review, 107, 60-80. https://doi.org/10.1016/j.tre.2017.09.006

Leitner, R., Meizer, F., Prochazka, M. \& Sihn, W. (2011). "Structural concepts for horizontal cooperation to increase efficiency in logistics". CIRP Journal of Manufacturing Science and Technology, 4, 332-337. http://dx.doi.org/10.1016/j.cirpj.2011.01.009

Li, J., Cai, X. \& Zeng, Y. (2016). "Cost allocation for less-than-truckload collaboration among perishable product retailers". OR Spectrum, 38, 81-117. 10.1007/s00291-015-0424-9

Li, J., Rong, G. \& Feng, Y. (2015). "Request selection and exchange approach for carrier collaboration based on auction of a single request". Transportation Research Part E: Logistics and Transportation Review, 84, 23-39. http://dx.doi.org/10.1016/j.tre.2015.09.010

Lin, D.-Y. \& Ng, K. H. (2012). "The impact of collaborative backhaul routing on carbon reduction in the freight industry". Transportation Research Part D: Transport and Environment, 17, 626-628. http://dx.doi.org/10.1016/j.trd.2012.08.002 
Lin, Y.-H., Meller, R. D., Ellis, K. P., Thomas, L. M. \& Lombardi, B. J. (2014). "A decomposition-based approach for the selection of standardized modular containers". International Journal of Production Research, 52, 4660-4672. $10.1080 / 00207543.2014 .883468$

Liu, R., Jiang, Z., Fung, R. Y. K., Chen, F. \& Liu, X. (2010a). "Two-phase heuristic algorithms for full truckloads multi-depot capacitated vehicle routing problem in carrier collaboration". Computers \& Operations Research, 37, 950-959. http://dx.doi.org/10.1016/j.cor.2009.08.002

Liu, R., Jiang, Z., Liu, X. \& Chen, F. (2010b). "Task selection and routing problems in collaborative truckload transportation". Transportation Research Part E: Logistics and Transportation Review, 46, 1071-1085. http://dx.doi.org/10.1016/j.tre.2010.05.003

Lozano, S., Moreno, P., Adenso-Diaz, B. \& Algaba, E. (2013). "Cooperative game theory approach to allocating benefits of horizontal cooperation". European Journal of Operational Research, 229, 444-452. http://dx.doi.org/10.1016/j.ejor.2013.02.034

Mason, R., Lalwani, C. \& Boughton, R. (2007). "Combining vertical and horizontal collaboration for transport optimisation". Supply Chain Management: An International Journal, 12, 187-199

McKinnon, A., Browne, M., Whiteing, A. \& Piecyk, M. (2015). Green logistics: Improving the environmental sustainability of logistics, Kogan Page Publishers.

Molenbruch, Y., Braekers, K. \& Caris, A. (2017). "Benefits of horizontal cooperation in diala-ride services". Transportation Research Part E: Logistics and Transportation Review, 107, 97-119. https://doi.org/10.1016/j.tre.2017.09.001

Montoya-Torres, J. R., Muñoz-Villamizar, A. \& Vega-Mejía, C. A. (2016). "On the impact of collaborative strategies for goods delivery in city logistics". Production Planning \& Control, $27,443-455$

Montreuil, B. (2011). "Toward a Physical Internet: meeting the global logistics sustainability grand challenge". Logistics Research, 3, 71-87. 10.1007/s12159-011-0045-x

Muñoz-Villamizar, A., Montoya-Torres, J. R. \& Faulin, J. (2017). "Impact of the use of electric vehicles in collaborative urban transport networks: A case study". Transportation Research Part D: Transport and Environment, 50, 40-54. https://doi.org/10.1016/j.trd.2016.10.018

Nagarajan, M. \& Sošić, G. (2008). "Game-theoretic analysis of cooperation among supply chain agents: Review and extensions". European Journal of Operational Research, 187, 719745

Özener, O. Ö. \& Ergun, Ö. (2008). "Allocating Costs in a Collaborative Transportation Procurement Network". Transportation Science, 42, 146-165. doi:10.1287/trsc.1070.0219

Özener, O. Ö., Ergun, Ö. \& Savelsbergh, M. (2011). "Lane-Exchange Mechanisms for Truckload Carrier Collaboration". Transportation Science, 45, 1-17. 10.1287/trsc.1100.0327

Padilla Tinoco, S. V., Creemers, S. \& Boute, R. N. (2017). "Collaborative shipping under different cost-sharing agreements". European Journal of Operational Research, 263, 827837. https://doi.org/10.1016/j.ejor.2017.05.013

Palhazi Cuervo, D., Vanovermeire, C. \& Sörensen, K. (2016). "Determining collaborative profits in coalitions formed by two partners with varying characteristics". Transportation Research Part C: Emerging Technologies, 70, 171-184. http://dx.doi.org/10.1016/j.trc.2015.12.011

Pan, S., Ballot, E. \& Fontane, F. (2013). "The reduction of greenhouse gas emissions from freight transport by pooling supply chains". International Journal of Production Economics, 143, 86-94. http://dx.doi.org/10.1016/j.ijpe.2010.10.023 
Pan, S., Ballot, E., Fontane, F. \& Hakimi, D. (2014). "Environmental and economic issues arising from the pooling of SMEs' supply chains: case study of the food industry in western France". Flexible Services and Manufacturing Journal, 26, 92-118. 10.1007/s10696-0129162-3

Pan, S., Ballot, E., Huang, G. Q. \& Montreuil, B. (2017a). "Physical Internet and interconnected logistics services: research and applications". International Journal of Production Research, 55, 2603-2609. 10.1080/00207543.2017.1302620

Pan, S., Nigrelli, M., Ballot, E., Sarraj, R. \& Yang, Y. (2015). "Perspectives of inventory control models in the Physical Internet: A simulation study". Computers \& Industrial Engineering, 84, 122-132. http://dx.doi.org/10.1016/j.cie.2014.11.027

Pan, S., Trentesaux, D. \& Sallez, Y. 2017b. Specifying Self-organising Logistics System: Openness, Intelligence, and Decentralised Control. In: Borangiu, T., Trentesaux, D., Thomas, A., Leitão, P. \& Oliveira, J. B. (eds.) Service Orientation in Holonic and Multi-Agent Manufacturing : Proceedings of SOHOMA 2016. Springer.

Pérez-Bernabeu, E., Juan, A. A., Faulin, J. \& Barrios, B. B. (2015). "Horizontal cooperation in road transportation: a case illustrating savings in distances and greenhouse gas emissions". International Transactions in Operational Research, 22, 585-606. 10.1111/itor.12130

Piecyk, M. I. \& McKinnon, A. C. (2010). "Forecasting the carbon footprint of road freight transport in 2020". International Journal of Production Economics, 128, 31-42. http://dx.doi.org/10.1016/j.ijpe.2009.08.027

Pomponi, F., Fratocchi, L. \& Tafuri, S. R. (2015). "Trust development and horizontal collaboration in logistics: a theory based evolutionary framework". Supply Chain Management: An International Journal, 20, 83-97. doi:10.1108/SCM-02-2014-0078

Power, D. (2005). "Supply chain management integration and implementation: a literature review". Supply chain management: an International journal, 10, 252-263

Puettmann, C. \& Stadtler, H. (2010). "A collaborative planning approach for intermodal freight transportation". OR Spectrum, 32, 809-830. 10.1007/s00291-010-0211-6

Qiao, B., Pan, S. \& Ballot, E. (2016). "Dynamic pricing model for less-than-truckload carriers in the Physical Internet". Journal of Intelligent Manufacturing, (in press), 1-13. $10.1007 / \mathrm{s} 10845-016-1289-8$

Raue, J. S. \& Wallenburg, C. (2013). "Alike or not? Partner similarity and its outcome in horizontal cooperations between logistics service providers". Logistics Research, 6, 217-230. 10.1007/s12159-013-0106-4

Rodrigues, V. S., Harris, I. \& Mason, R. (2015). "Horizontal logistics collaboration for enhanced supply chain performance: an international retail perspective". Supply Chain Management: An International Journal, 20, 631-647

Rossi, S. 2012. Challenges for Co-Modality in a Collaborative Environment (CO3 Project Position Paper).

Saenz, M. J., Ubaghs, E. \& Cuevas, A. I. (2015). Enabling Horizontal Collaboration Through Continuous Relational Learning, Springer International Publishing.

Sallez, Y., Pan, S., Montreuil, B., Berger, T. \& Ballot, E. (2016). "On the activeness of intelligent Physical Internet containers". Computers in Industry, 81, 96-104. http://dx.doi.org/10.1016/j.compind.2015.12.006

Sarraj, R., Ballot, E., Pan, S., Hakimi, D. \& Montreuil, B. (2014a). "Interconnected logistic networks and protocols: simulation-based efficiency assessment". International Journal of Production Research, 52, 3185-3208 
Sarraj, R., Ballot, E., Pan, S. \& Montreuil, B. (2014b). "Analogies between Internet network and logistics service networks: challenges involved in the interconnection". Journal of Intelligent Manufacturing, 25, 1207-1219. 10.1007/s10845-012-0697-7

Schmoltzi, C. \& Wallenburg, C. M. (2011). "Horizontal cooperations between logistics service providers: motives, structure, performance". International Journal of Physical Distribution \& Logistics Management, 41, 552-575

Schmoltzi, C. \& Wallenburg, C. M. (2012). "Operational Governance in Horizontal Cooperations of Logistics Service Providers: Performance Effects and the Moderating Role of Cooperation Complexity". Journal of Supply Chain Management, 48, 53-74. 10.1111/j.1745493X.2011.03262.x

Soysal, M., Bloemhof-Ruwaard, J. M., Haijema, R. \& van der Vorst, J. G. A. J. (2018). "Modeling a green inventory routing problem for perishable products with horizontal collaboration". Computers \& Operations Research, 89, 168-182. https://doi.org/10.1016/j.cor.2016.02.003

Spekman, R. E., Kamauff Jr, J. W. \& Myhr, N. (1998). "An empirical investigation into supply chain management: a perspective on partnerships". Supply Chain Management: An International Journal, 3, 53-67

Stadtler, H. (2009). "A framework for collaborative planning and state-of-the-art". OR Spectrum, 31, 5-30. 10.1007/s00291-007-0104-5

van Duin, J. H. R., Tavasszy, L. A. \& Taniguchi, E. (2007). "Real time simulation of auctioning and re-scheduling processes in hybrid freight markets". Transportation Research Part B: Methodological, 41, 1050-1066. http://dx.doi.org/10.1016/j.trb.2007.04.007

Vanovermeire, C. \& Sörensen, K. (2014a). "Integration of the cost allocation in the optimization of collaborative bundling". Transportation Research Part E: Logistics and Transportation Review, 72, 125-143. http://dx.doi.org/10.1016/j.tre.2014.09.009

Vanovermeire, C. \& Sörensen, K. (2014b). "Measuring and rewarding flexibility in collaborative distribution, including two-partner coalitions". European Journal of Operational Research, 239, 157-165. http://dx.doi.org/10.1016/j.ejor.2014.04.015

Vanovermeire, C., Sörensen, K., Van Breedam, A., Vannieuwenhuyse, B. \& Verstrepen, S. (2014). "Horizontal logistics collaboration: decreasing costs through flexibility and an adequate cost allocation strategy". International Journal of Logistics Research and Applications, 17, 339-355. 10.1080/13675567.2013.865719

Verdonck, L., Beullens, P., Caris, A., Ramaekers, K. \& Janssens, G. K. (2016). "Analysis of collaborative savings and cost allocation techniques for the cooperative carrier facility location problem". Journal of the Operational Research Society, 67, 853-871

Verdonck, L., Caris, A. N., Ramaekers, K. \& Janssens, G. K. (2013). "Collaborative Logistics from the Perspective of Road Transportation Companies". Transport Reviews, 33, 700-719. 10.1080/01441647.2013.853706

Verstrepen, S., Cools, M., Cruijssen, F. \& Dullaert, W. (2009). "A dynamic framework for managing horizontal cooperation in logistics". International Journal of Logistics Systems and Management, 5, 228-248

Wallenburg, C. M. \& Raue, J. S. (2011). "Conflict and its governance in horizontal cooperations of logistics service providers". International Journal of Physical Distribution \& Logistics Management, 41, 385-400

Wang, H., Unnikrishnan, A., Hernández, S. \& Cheu, R. (2014a). "Capacitated Centralized Carrier Collaboration Multihub Location Problem: Tabu Search Approach". Transportation Research Record: Journal of the Transportation Research Board, 22-30 
Wang, X. \& Kopfer, H. (2014). "Collaborative transportation planning of less-than-truckload freight". OR Spectrum, 36, 357-380. 10.1007/s00291-013-0331-x

Wang, X. \& Kopfer, H. (2015). "Rolling horizon planning for a dynamic collaborative routing problem with full-truckload pickup and delivery requests". Flexible Services and Manufacturing Journal, 27, 509-533. 10.1007/s10696-015-9212-8

Wang, X., Kopfer, H. \& Gendreau, M. (2014b). "Operational transportation planning of freight forwarding companies in horizontal coalitions". European Journal of Operational Research, 237, 1133-1141. http://dx.doi.org/10.1016/j.ejor.2014.02.056

Wang, Y., Rodrigues, V. S. \& Evans, L. (2015). "The use of ICT in road freight transport for $\mathrm{CO} 2$ reduction - an exploratory study of UK's grocery retail industry". The International Journal of Logistics Management, 26, 2-29. doi:10.1108/IJLM-02-2013-0021

Xu, S. X. \& Huang, G. Q. (2013). "Transportation service procurement in periodic sealed double auctions with stochastic demand and supply". Transportation Research Part B: Methodological, 56, 136-160. http://dx.doi.org/10.1016/j.trb.2013.07.015

Xu, S. X. \& Huang, G. Q. (2014). "Efficient auctions for distributed transportation procurement". Transportation Research Part B: Methodological, 65, 47-64

Xu, S. X., Huang, G. Q. \& Cheng, M. (2016). "Truthful, budget-balanced bundle double auctions for carrier collaboration". Transportation Science, 51, 1365 - 1386

$\mathrm{Xu}$, X. 2013. Collaboration Mechanism in the Horizontal Logistics Collaboration. Ph.D., MINES ParisTech.

Yang, F., Yang, M., Xia, Q. \& Liang, L. (2015). "Collaborative distribution between two logistics service providers". International Transactions in Operational Research. 10.1111/itor.12158

Yang, Y., Pan, S. \& Ballot, E. (2017a). "Innovative vendor managed inventory strategy exploiting interconnected logistics services in the Physical Internet ". International Journal of Production Research, 55, 2685-2702. http://dx.doi.org/10.1080/00207543.2016.1275871

Yang, Y., Pan, S. \& Ballot, E. (2017b). "Mitigating supply chain disruptions through interconnected logistics services in the Physical Internet". International Journal of Production Research, 55, 3970-3983. 10.1080/00207543.2016.1223379

Yilmaz, O. \& Savasaneril, S. (2012). "Collaboration among small shippers in a transportation market". European Journal of Operational Research, 218, 408-415. http://dx.doi.org/10.1016/j.ejor.2011.11.018

Zacharia, Z. G., Sanders, N. R. \& Nix, N. W. (2011). "The Emerging Role of the Third-Party Logistics Provider (3PL) as an Orchestrator". Journal of Business Logistics, 32, 40-54

Zhang, M., Pratap, S., Huang, G. Q. \& Zhao, Z. (2017). "Optimal collaborative transportation service trading in B2B e-commerce logistics". International Journal of Production Research, 55, 5485-5501. 10.1080/00207543.2017.1322731

Zhou, G., Hui, Y. V. \& Liang, L. (2011). "Strategic alliance in freight consolidation". Transportation Research Part E: Logistics and Transportation Review, 47, 18-29. http://dx.doi.org/10.1016/j.tre.2010.07.002

Zhu, Z., Chu, F., Dolgui, A., Chu, C., Zhou, W. \& Piramuthu, S. (2018). "Recent advances and opportunities in sustainable food supply chain: a model-oriented review". International Journal of Production Research, 1-23. 10.1080/00207543.2018.1425014 